\title{
Rapid, direct and non-destructive assessment of fossil organic matter via microRaman spectroscopy
}

\section{Citation}

Ferralis, Nicola, Emily D. Matys, Andrew H. Knoll, Christian Hallmann, and Roger E. Summons. 2016. "Rapid, Direct and Non-Destructive Assessment of Fossil Organic Matter via microRaman Spectroscopy." Carbon 108 (November): 440-449. doi:10.1016/j.carbon.2016.07.039.

\section{Published Version}

doi:10.1016/j.carbon.2016.07.039

\section{Permanent link}

http://nrs.harvard.edu/urn-3:HUL.InstRepos:33973837

\section{Terms of Use}

This article was downloaded from Harvard University's DASH repository, and is made available under the terms and conditions applicable to Open Access Policy Articles, as set forth at http:// nrs.harvard.edu/urn-3:HUL.InstRepos:dash.current.terms-of-use\#OAP

\section{Share Your Story}

The Harvard community has made this article openly available.

Please share how this access benefits you. Submit a story.

Accessibility 


\title{
Rapid, direct and non-destructive assessment of fossil organic matter via microRaman spectroscopy
}

Nicola Ferralis ${ }^{\mathrm{a}, 1}$ Emily D. Matys ${ }^{\mathrm{b}}$, Andrew H. Knoll ${ }^{\mathrm{c}}$, Christian Hallmann ${ }^{\mathrm{b}, \mathrm{d}}$, Roger E. Summons ${ }^{\mathrm{b}, 1}$

${ }^{a}$ Department of Materials Science and Engineering, Massachusetts Institute of Technology, Cambridge, MA 02139, USA

${ }^{b}$ Department of Earth Atmospheric and Planetary Sciences, Massachusetts Institute of Technology, Cambridge, MA 02139, USA

${ }^{\mathrm{c}}$ Department of Organismic and Evolutionary Biology, Harvard University, Cambridge, MA 02138, USA

${ }^{\mathrm{d}}$ Present address: Max Planck Institute for Biogeochemistry, Jena, Germany and MARUM, University of Bremen, Germany.

${ }^{1}$ To whom the correspondence may be addressed. Email: ferralis@mit.edu and rsummons@mit.edu

A manuscript prepared for Carbon

\begin{abstract}
Raman spectroscopy is widely used to evaluate the nature and potential origins of carbonaceous matter in Earth's oldest rocks and minerals. It is also the tool that will be used for organic detection on the next vehicles to remotely explore the surface of Mars. Here we present, for the first time, a novel quantitative method in which previously neglected Raman spectral features are correlated directly, linearly, and with excellent accuracy, to the microchemistry of carbonaceous materials through the elemental $\mathrm{H}: \mathrm{C}$ ratio, regardless of contamination. We show applicability and predictive capabilities of this methodology in evaluating $\mathrm{H}: \mathrm{C}$ ratios between 0.01 and 0.65 in Archean and type III kerogens. We demonstrate its application to chemical microRaman mapping by statistical analysis of a 750Ma microfossil and its encompassing sediments. Raman-derived $\mathrm{H}: \mathrm{C}$ data can also be used to estimate the degree to which kerogen $\mathrm{C}$-isotopic data has been shifted from its original values due to the effects of metamorphism. The new methodology directly and non-invasively affords spatially resolved assessments of organic matter preservation and microscale chemical diversity within any geologically
\end{abstract}


preserved terrestrial or extraterrestrial sample, including in the use of organic matter in technological applications.

\section{Introduction}

The demonstrated facile, and non-destructive deployment of Raman spectroscopy to identify key chemical parameters in organic matter makes it extremely compelling for spatially-resolved quantitative geological and petrochemical surveys of the chemistry of organic matter (OM), as well as for the recent innovative use of OM for technological applications, such as thin films for electronics [1]. Several techniques can spatially resolve carbon chemistry such as laser desorption ionization (LDI) coupled to Fourier transform ion cyclotron resonance mass spectrometry (FTICR-MS) and Time-of-Flight Secondary Ion Mass Spectrometry (TOF-SIMS) [2, 3]. Yet, Raman spectroscopy has the potential to allow quantitative evaluation of carbon chemistry, while non-invasively preserving the specimen chemistry and morphology, and with minimal specimen preparation. Such flexibility is particularly of interest for its application to detection and characterization of organic matter were sample preservation is essential, such as for organic fossils, both in terrestrial and - potentially - extraterrestrial samples [4-6].

A resurgence in interest in quantitative assessments of carbon chemistry of highly aromatic organic matter is also motivated by the challenges in understanding in the origins and early evolution of life on the Earth and, possibly, elsewhere in the solar system, which has been heightened by recent successes of NASA's Mars Science Laboratory Mission. Sedimentological and geochemical features of ancient sedimentary rocks indicate the presence in Mars' past of potentially habitable environments characterized by the extended presence of standing water [7]. A complementary search for indigenous, well-preserved OM, however, has been less conclusive, this due in part, by the lack of a spatially resolved quantitative method for rapid screening of chemical preservation of OM. For example, to date, discoveries have been limited to the detection

of small organic molecules during pyrolysis-gas chromatography-mass spectrometry (pyGC-MS) experiments in Mars [8]. On Mars, the search for preserved organic matter, and 
the determination of its chemical composition, has been particularly hindered by the highly reactive, strongly oxidizing nature of surface sediments activated by the invasive, high energy probe, which present obstacles to both preservation and the thermal volatilization and pyrolysis approaches for detection that have so far been deployed in landed missions [9-12].

Similarly, the analysis of OM in Earth's oldest sedimentary rocks has been subject to multiple combinations of problems. OM is ubiquitous in ancient terrestrial sediments and often occurs in great abundance, even in rocks more than 2.5 billion years old [13-15]. Here, the key problems are interpretive and revolve around establishing whether or not preserved organic molecules are syngenetic and indigenous to the rocks in which they occur $[16,17]$, identifying and excluding contamination artifacts [18] and seeing past the destructive and confounding effects of thermal metamorphism [15] and ionizing radiation [19].

Raman spectroscopy and microscopy have been used extensively to characterize, often with submicron spatial resolution the OM of kerogens and microscopic fossils in both sedimentary rocks [20] and extra-planetary materials [21-24]. In particular, laser-Raman mapping with submicron-scale resolution was used to establish positive correlations between optically discernible microscopic fossils and the carbonaceous nature of their preserved walls or envelopes [25-27]. In studies of interplanetary dust particles and meteorites, Raman spectroscopy conducted at sub-micron resolution is able to identify heterogeneities in chemical composition of the OM, a feature that speaks to its origin by means of multiple chemical processes [24, 28].

Many authors have identified systematic changes in Raman spectra that accompany the thermal maturation and metamorphism of sediments. Comparative analyses of metamorphic rocks in relation to their thermal maturation document the evolution of the Raman D bands and the sharpening of the G band (Fig. 1) as a result of the progressive graphitization of sedimentary OM [29-33]. Similarly, early observations of Precambrian kerogens suggested that loss of the $\mathrm{D}$ band and sharpening of the $\mathrm{G}$ band accompanied 
increasing metamorphic grade [34], while Schopf and colleagues developed a Raman Index of Preservation (RIP) [35] and observed positive correlations with Raman-based parameters, $\mathrm{H}: \mathrm{C}$ and other indices of the maturity of microscopic fossils. Conversely, other techniques (such as FTIR) can provide a semi-quantitative, spatially resolved assessment of functional chemistry for biological and low maturity kerogen [36], and yet, any chemical assessment is qualitative at best for mature OM by the very low spectral contribution from aliphatics, while being predominantly dominated by aromatic compounds [37].

In the present study, we build on this foundation and document a novel suite of microchemical characterization tools that allow in situ, non-destructive, and unique approximation of the $\mathrm{H}: \mathrm{C}$ ratio of mature organic matter from the micron to the millimeter scale. We provide accurate direct calibrations of the spectral response of a suite of chemically diverse, mature organic matter samples to elemental $\mathrm{H}: \mathrm{C}$ for a range between 0.01 and 0.65 using Raman spectroscopy. The spatial upscaling enabled by the technique is designed to provide a maturity population distribution from the nanoscale to conventionally used macro-scale averaged parameters (such as vitrinite reflectance). The derivation of elemental $\mathrm{H}: \mathrm{C}$ ratios directly from analyses of Raman spectra affords a tool for rapidly and remotely evaluating bulk OM composition on future missions to Mars. On

Earth, the approach is ideal for facile and inexpensive examination of spatial variations in the chemical composition of microscopic fossils or the regional maturity trends across sedimentary basins in order to identify the best preserved organic matter for more detailed geobiological study. It can be immediately used to determine $\mathrm{H}: \mathrm{C}$ for OMderived electronic grade thin films and therefore infer their optical properties [38].

\section{Materials and Methods}

2.1 Raman spectroscopy. Micro-Raman spectra were acquired using a Horiba LabRAM $800 \mathrm{HR}$ spectrometer in a confocal configuration equipped with a $\mathrm{He}-\mathrm{Ne}(632.817 \mathrm{~nm})$ laser as the excitation source and a Peltier-cooled CCD detector. The laser was focused on the sample with a $400 \mathrm{~nm}$ confocal hole using the 100X objective under reflected illumination. The laser spot on the sample was $\sim 800 \mathrm{~nm}$ in diameter and had a power of 
$\sim 4 \mathrm{~mW}$ at the sample surface. A calibrated edge high band filter (lowest wavenumber:

$\sim 70 \mathrm{~cm}^{-1}$ ) was used to minimize the elastic backscattered signal. The method for spectral fitting and background subtraction can be found in SI.

2.2 Cluster Analysis of Raman maps. Identification of clusters or phases within a map through correlation of Raman spectral features are carried out using cluster analysis based on the mixture modeling [39] as implemented in the R-package MClust [40, 41]. Further details in the SI.

2.3 Isolated Kerogen Samples. Kerogen samples (Table S1) with a well-characterized as well as uniform chemical fingerprint ( $\mathrm{H}: \mathrm{C}$ and mineralogy) were chosen for the calibration of Raman spectral features such as intensity peak ratios with macroscopic H:C ratios (between 0.01 and 0.65 by elemental analysis). For the purpose, a total of 16 samples (age range: 1.4-3.9 Gy) from the Precambrian Paleobiology Research Group (PPRG) [42], were provided by JW Schopf. Isolated type III kerogens from the Penn State Coal bank (Department of Energy Coal Samples - DECS) were used were also used. Additional samples from two Agouron Institute Drilling Projects in Australia (samples with the AIDP identifier) and South Africa (Samples with the GKF and GKP identifiers), which were used in recent geochemical studies of organic matter-rich Neoarchean sediments from the Pilbara [43, 44] and Kaapvaal Cratons [14, 18, 45-48] were included to evaluate their $\mathrm{H}: \mathrm{C}$ using the calibration above. Details of kerogen selection and isolation are available in SI.

2.4 Organic Fossil. The application of the novel Raman method here developed to mapping was done using a thin section of silicified coastal carbonate containing organically preserved fossils of the protist Trachyhystrichosphaera aimika, from the 750 Ma Draken Formation, Spitsbergen. The fossil is deposited in the Paleobotanical Collections of the Harvard University Herbaria, collection number 62371.

\section{Results and discussion}


The conventional approach to interpreting Raman spectra relies on characterization of the intensity and width of two of the major bands, the G peak and D peak complex [49] (Fig. 1). The $\mathrm{G}$ peak (at $1582 \mathrm{~cm}^{-1}$ ) is related to an in-plane $\mathrm{sp}^{2}$ bond stretching shear vibration within the aromatic ring in a large, graphene-like cluster. The full-width, half-max of the G peak $(F W H M) \omega_{G}$ increases monotonically with the degree of disorder in the graphitic lattice [49], either by defects within the aromatic clusters or through scattering by their edges. In the context of $\mathrm{OM}$, it is expected that the size of aromatic clusters will increase with maturity, hence a correlation between $\omega_{\mathrm{G}}$ and maturity is expected. To test this hypothesis, we extracted $\omega_{\mathrm{G}}$ from a set of previously well-studied kerogens from the collection of the Precambrian Paleobiology Research Group (PPRG), Table S1 [50].

The data are plotted against the nominal $\mathrm{H}: \mathrm{C}$ ratio of each sample (Fig. S1). The correlation, while acceptable, is indirect: $\omega_{\mathrm{G}}$ is related only to the size of aromatic clusters, which themselves are not directly related to $\mathrm{H}: \mathrm{C}$. Therefore, it is expected that the double correlation between $\omega_{\mathrm{G}} v s$ maturity and maturity $v s \mathrm{H}: \mathrm{C}$ will lead to a correlation between $\omega_{\mathrm{G}}$ and $\mathrm{H}: \mathrm{C}$. In essence, while $\omega_{\mathrm{G}}$ can be used to represent the maturation process of a given OM, it does not represent a proxy for a defined chemical entity such as the elemental $\mathrm{H}: \mathrm{C}$ ratio. The limitation of such correlations to aromatic hydrocarbons hinders their applicability to complex non-aromatic functional groups present in OM. Furthermore, in the case of low maturity OM, the estimation of $\omega_{G}$ is further complicated by the presence of a shoulder band D2 related to intravalley defects in the aromatic structure [51]. Accounting for D2 may ultimately be possible for high maturity $\mathrm{O}$, where the peak can distinctively be separated from the $\mathrm{G}$ peak and $\omega_{\mathrm{D} 2}$ (FWHM(D2)) and effectively be used in itself as a maturity indicator [52]. However, its range of applicability is ultimately restricted to the case where it can be deconvoluted from the $\mathrm{G}$ peak. 


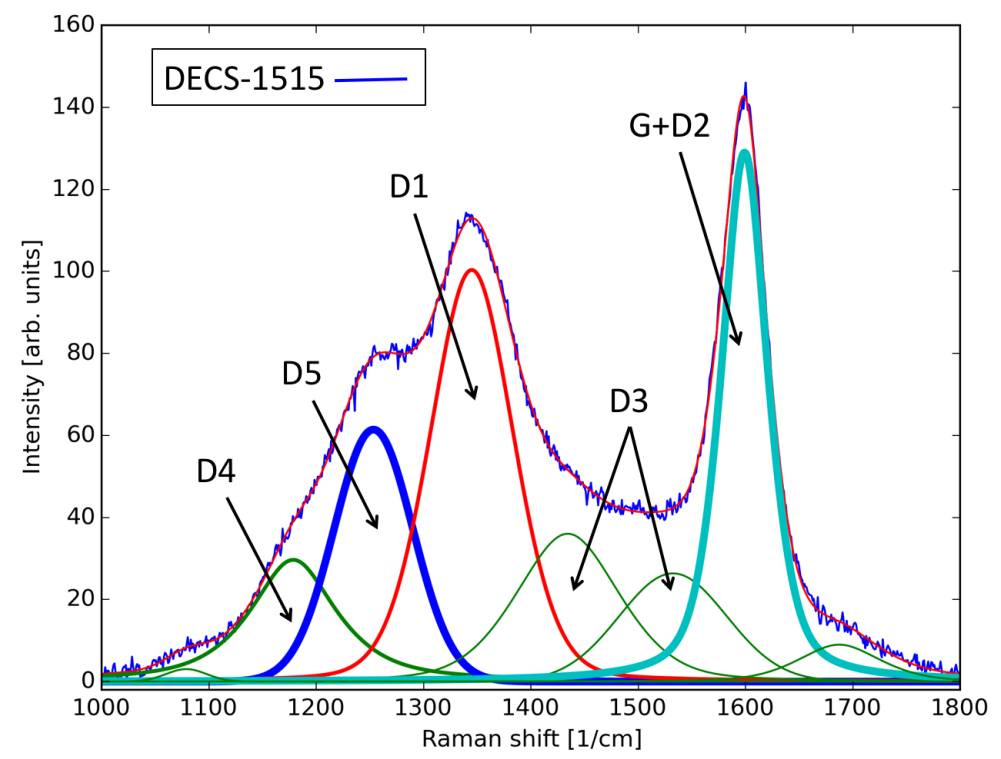

Figure 1 Raman spectrum of kerogen type III, (Department of Energy Coal Samples - DECS1515 from the Penn State coal bank, details in Supplementary information). The fit is performed as described in the Methods, and the final bands obtained from the fit are identified.

The complex structure of the D band is highlighted by the presence of several sub-bands [53-55] (Fig.1). Because of its highly convoluted nature, complex fitting procedures are required to identify each sub-band within the D complex. Among them, the D1 peak ( $\left.1340 \mathrm{~cm}^{-1}\right)$ is usually predominant and is only sub-band present in graphitic carbon. The D1 peak corresponds to the breathing mode of the $\mathrm{sp}^{2}$ aromatic ring within a graphitic cluster [49]. This peak is highly resonant, which means that the optical response is strongly influenced by the electronic structure of the local environment. Conventionally, several variations of ratio of D1 and G peak amplitudes (D1/G) or integrated intensities $(\mathrm{D} 1 /(\mathrm{D} 1+\mathrm{G}))$ have been used to correlate with the size of the graphic clusters, measured using x-ray diffraction. Beginning with the work of Tuinstra and Koenig [56] multiple correlations have been explored to account for the excitation energy of the laser [57, 58]. The correlation between the integrated intensities of $\mathrm{D} 1 / \mathrm{G}$ and maturity has been proven fairly successful, but only under metamorphic conditions ( $\mathrm{H}: \mathrm{C}<0.3-0.4)[59]$ where $\mathrm{OM}$ has an extensive and predominant aromatic and graphitic character (well above $90 \%$ [60]). Since both the D1 and G peaks represent vibrations within aromatic rings, it is 
expected that any evolution in size and order of the D1 and G peak will correlate, approximately, with other proxies for maturity (including burial temperature). A similar argument was made for the width of the D1 peak (FWHM(D1)) as correlated to maturity [52] and showing a good correlation with burial temperature down to $150{ }^{\circ} \mathrm{C}$. However, when a non-negligible fraction of $\mathrm{H}$ is within a non-aromatic structure in $\mathrm{OM}$, this correlation no longer applies $[6,37,61]$ or at least is not necessarily expected. Indeed, when $\mathrm{D} 1 /(\mathrm{G}+\mathrm{D} 2)$ vs $\mathrm{H}: \mathrm{C}$ is plotted for the PPRG sample set (Fig. S4), the correlation is poor, mainly for higher values of $\mathrm{H}: \mathrm{C}$, where aliphatic components are not negligible in OM, but also in the regime where $\mathrm{D} 1 / \mathrm{G}$ is well correlated with burial temperature. Similarly to the relation with $\omega_{\mathrm{G}}$, a set of spectral features that originate uniquely from aromatic fragments within $\mathrm{OM}$ (such as D1, G, D2) and that are highly sensitive to structural disorder in the aromatics (like D1, D2), D1/(G+D2) cannot reliably represent the real $\mathrm{H}: \mathrm{C}$ in presence of a more diverse functional chemistry. Similarly, it does not favor the extraction of chemical information from structurally similar, but chemically different OM. This issue is similar to the use of vitrinite reflectance (VRo), the optical response of a particular maceral, to evaluate the maturity for any $\mathrm{OM}$ as different $\mathrm{OM}$ with different aromatic content and $\mathrm{H}: \mathrm{C}$ may have the same VRo, limiting the predictive nature of the chemical variability of different OM types [62].

The D4 and D5 peaks (at $\sim 1150$ and $\sim 1265 \mathrm{~cm}^{-1}$ respectively, Fig. 1) often appear as broad shoulders of the D1 peak at $1330 \mathrm{~cm}^{-1}$ [53] and are less well understood. Neither peak is present among carbonaceous and graphitic materials: for example, these peaks are absent in purely graphitic or highly carbonized materials, while they appear in fairly immature $\mathrm{OM}$ or in functionalized carbon systems, both natural (e.g. fatty acids [63, 64] and synthetic (e.g. nano-diamond [65]). The most common interpretations of the origin of the $\mathrm{D} 4$ peak focus on vibrations of $\mathrm{C}_{\text {aromatic }}-\mathrm{C}_{\text {alkyl}}$; aromatic aryl-alkyl ethers, $\mathrm{C}-\mathrm{C}$ in aromatic rings and $\mathrm{C}-\mathrm{H}$ in aromatic rings [55], as well as trans-polyene-like $\mathrm{C}-\mathrm{C}$ and $\mathrm{C}=\mathrm{C}$ stretch bonds $[54,65]$. Despite the origin of D5 $\left(\sim 1270 \mathrm{~cm}^{-1}\right)$ not being currently well understood, it was used along with D4 and D1 by Schopf and colleagues to define the Raman Index of Preservation [35]. Whereas the integrated intensity of the Raman spectra between 1100 and $1300 \mathrm{~cm}^{-1}$ was decreasing in relation to the integrated intensity 
of the whole D complex $\left(1100-1500 \mathrm{~cm}^{-1}\right)$ the RIP was found to be empirically correlated with both $\mathrm{H}: \mathrm{C}$ and $\mathrm{N}: \mathrm{C}$.

The physical origin of D1 is well understood in terms of the double resonance phenomena in aromatic and graphitic carbon, which requires the presence of a defect in the aromatic texture (such as vacancies, heteroatoms and functional groups) for its initiation [66]. Yet, it is counterbalanced by the lack of a unique explanation for the origin of D4 and D5, neither of which can be explained by the defect-induced double resonance phenomena. Vibrations in the region associated with D5 $\left(\sim 1270 \mathrm{~cm}^{-1}\right)$ are often found to be related to the presence of methyl groups in either saturated and unsaturated alkane chains, such as $\mathrm{CH}_{2}$ twist, rock, and deformation modes in oleic, petroselinic and linoleic fatty acids [63]. These vibrations are usually associated with the identification of particular types of lipids in tissues from cancer diagnostics [67] to food science [68-71]. Furthermore, strong bands related to stretching modes $(\mathrm{v}(\mathrm{CC}))$ in alkanes appear up to $1300 \mathrm{~cm}^{-1}$, with broad variations below this frequency threshold [72, 73]. For example, in long chain methylene systems several twisting modes of $\mathrm{CH} 2$ modes take place in the D4-D5 region, from 1150 and $1300 \mathrm{~cm}^{-1}$ [72]. Therefore, D5 is uniquely related to vibrations originating from aliphatic hydrocarbon chains. In addition to a strong contribution from C-C vibration typically associated with aliphatic functionals to D4, D5 is poised to represent functional groups that are not associated with aromatic or graphitic systems. Non-aromatic functionalities at the aromatic edges (from methyl groups to alkanes or alkenes) do not significantly alter the fundamental vibrations of large aromatic and graphitic systems towards the D4-D5 region and they rather contribute to spectral intensity in the D4-D5 region instead [72]. A more comprehensive discussion on the origin of the D4-D5 bands can be found in the supplementary information. In this work, we assign spectral features that follow, independently, the evolution of aromatic clusters and aliphatic functionals with increasing maturation. In light of the diverse chemical origin of the D4-D5 and G peaks, we define two metrics that follow directly the evolution of a chemically relevant parameter (such as $\mathrm{H}: \mathrm{C}$ ) rather than maturity indexes that are either non-chemically defined (such as burial temperature) or only indirect or sample specific (Vitrinite reflectance or pyrolysis byproduct). 
Ideally, the distinct nature of the D4 and D5 peaks from D1 would allow for perfect statistical independence, so that the integrated intensity over the region corresponding to each peak would suffice for analysis. However, the broadness and close proximity of such peaks in the form of shoulder fundamentally limit the applicability of this method, as the contribution to the intensity from the tail of a peak (from D1, for example) is accounted in the intensity from the others. To limit the contribution from neighboring peaks, a PseudoVoigt peak fit is performed as described in the Methods.

In devising a metric that independently tracks Raman peaks associated with aliphatics and aromatics, we further limit the contribution to aliphatic peaks such as D4 and D5 from neighboring peaks that originate from aromatics by tracking the integrated intensity of the G and D2 bands, rather than D1. While, G and D2 have physically different origin within an aromatic or graphitic cluster, their presence is strictly related to the aromatic component only. Ideally, given D2 variability both in intensity and width as function of defects (such as physical defects in the aromatic structure or presence of heteroatoms), $G$ alone would serve as the ideal reference band for aromatic. Yet, for smaller aromatic clusters in low maturity OM, the blueshift of the $\mathrm{G}$ peak towards higher wavenumbers due to confinement effects leads to the $\mathrm{G}$ and D2 peaks merging into a single broad peak $[4,33,74]$. Therefore, within this work, we use the sum of the integrated intensity of the fitted G and D2 peaks when the peak can be discriminated or, otherwise, the overall fit of the $\mathrm{G}+\mathrm{D} 2$ band. We note that this method allows for the elimination from any crosscontribution from D1 to D4 and D5. Indeed, when ID5/(IG+ID2) or the $(\mathrm{ID} 4+\mathrm{ID} 5) /(\mathrm{IG}+\mathrm{ID} 2)$ are plotted against $\mathrm{ID} 1 /(\mathrm{IG}+\mathrm{ID} 2)$ no meaningful correlation is found (Fig. S5). 


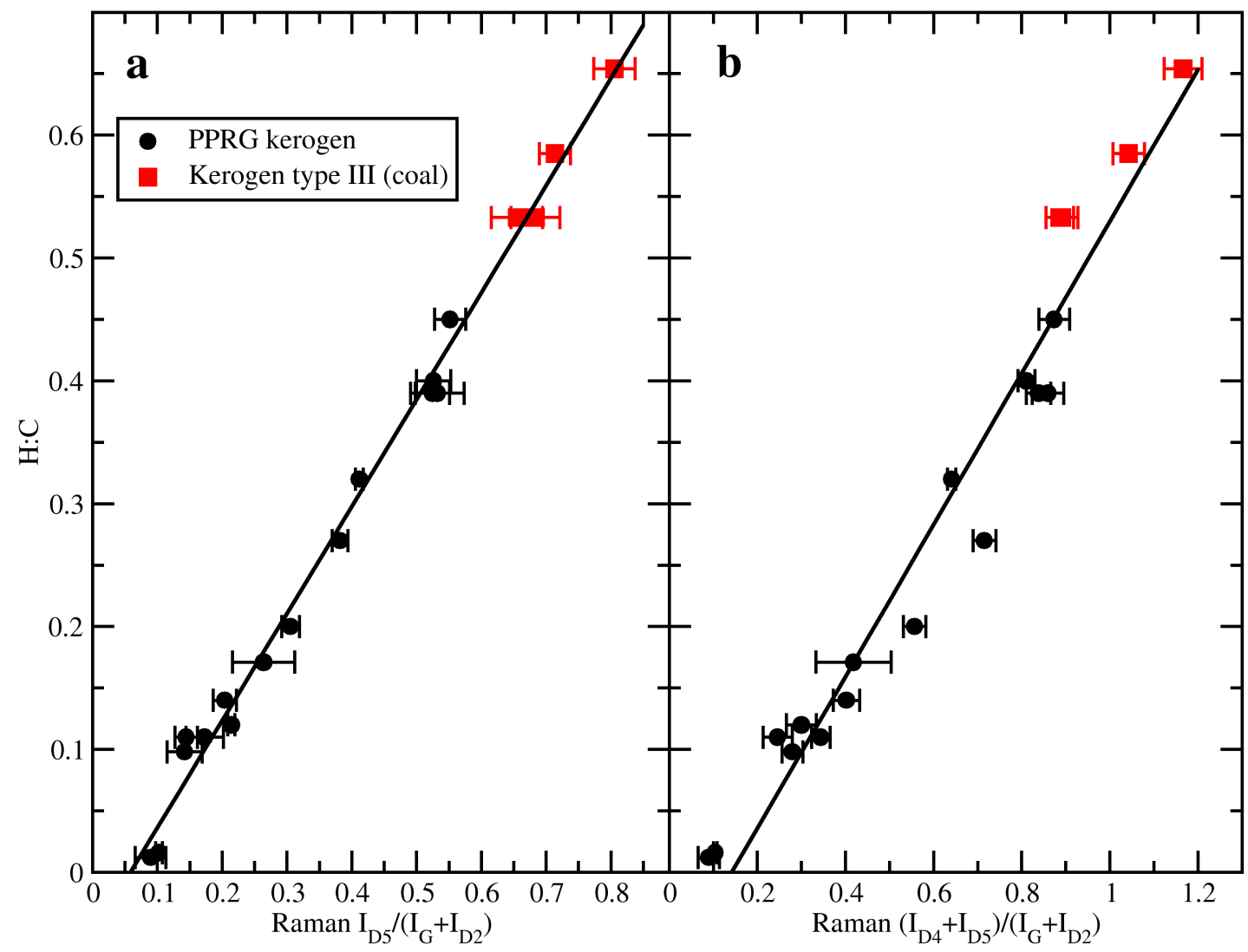

Figure 2 Correlations between the Raman intensity peak ratios: a) D5/(G+D2) and H:C and b) (D4+D5)/(G+D2) and H:C for the Precambrian kerogen (PPRG) and the kerogen type III (Table S1).

Fig. 2a shows the strong positive correlation between the ratio of the integrated intensities of the D5 and G+D2 bands and $\mathrm{H}: \mathrm{C}$ for the Precambrian (PPRG) and type III kerogen (coal):

$$
\begin{gathered}
\mathrm{H}: \mathrm{C}=0.871 \bullet \mathrm{I}_{\mathrm{D} 5} / \mathrm{I}_{\mathrm{G}+\mathrm{D} 2}-0.0508 \\
\mathrm{R}^{2}=0.9924
\end{gathered}
$$

The excellent agreement within the range of $\mathrm{H}: \mathrm{C}$ between 0 and 0.65 clearly shows that the integrated intensity ratio of the $\mathrm{C}-\mathrm{H}$ related $\mathrm{D} 5$ peak with the aromatic $\mathrm{G}+\mathrm{D} 2$ peak is directly correlated to the distribution of $\mathrm{H}: \mathrm{C}$ between aliphatic and aromatic moieties in kerogen, with no significant relation to their aromatic nanostructure (such as aromatic cluster size), unlike $\mathrm{D} 1 / \mathrm{G}$ or $\omega_{\mathrm{G}}$. This strong correlation supports our interpretation of the 
origin of the $\mathrm{D} 5$ peak based on $\mathrm{C}$ and $\mathrm{H}$ within aliphatic chains. A similar correlation is found for the ratio:

$$
\begin{aligned}
(\mathrm{D} 4+\mathrm{D} 5) /(\mathrm{G}+\mathrm{D} 2)(\text { Fig. } 2 \mathrm{~b}, \mathrm{H}: \mathrm{C} & =0.6024 \bullet\left(\mathrm{I}_{\mathrm{D} 4}+\mathrm{I}_{\mathrm{D} 5}\right) / \mathrm{I}_{\mathrm{G}+\mathrm{D} 2}-0.0739 \\
\mathrm{R}^{2} & =0.9548
\end{aligned}
$$

To our knowledge, this is the first time a linear, direct relation is proposed that links a Raman spectral feature to elemental $\mathrm{H}: \mathrm{C}$. We note that for highly mature kerogens ( $\mathrm{H}: \mathrm{C}$ $<0.15$ ), the very low concentration of aliphatics and related $\mathrm{C}-\mathrm{H}$ groups results in a strong reduction in intensity of the D5 peak. The persistence of the D4 peak under these conditions, where aliphatic carbons are not expected, can be attributed to the presence of $\mathrm{C}-\mathrm{C}$ on aromatic rings that may persist at higher maturity [55]. As the intensity of D5 may approach negligible values at high maturity, making the fit more unreliable, (D4+D5)/(G+D2) may be better suited for $\mathrm{H}: \mathrm{C}<0.15$.

The higher limit for the estimate of H:C from D5/(G+D2) and (D4 + D5)/(G+D2) is imposed uniquely by the ability to discriminate accurately between the D5 and G peak intensity of a given spectrum and its fluorescence-induced background. With a $633 \mathrm{~nm}$ excitation wavelength, the onset of strong fluorescence is for $\mathrm{H}: \mathrm{C} \sim 0.6-0.65$. However, instruments using higher energy excitations up to UV, such SHERLOC, slated to fly on the Mars2020 rover mission [75] would either limit fluorescence or completely remove it, allowing for the application of this method beyond current limits.

The correlation found between the RIP index and N:C (in addition to H:C, Schopf et al. $2005)$ might cast doubt on the relation with between $\mathrm{D} 5 /(\mathrm{G}+\mathrm{D} 2)$ and $\mathrm{H}: \mathrm{C}$ inferring that is not a direct consequence to the physical interpretation of the origin of the D5, G and D2 bands and can be potentially affected by heteroatoms. However, the very poor correlation between $\mathrm{D} 5 /(\mathrm{G}+\mathrm{D} 2)$ and $\mathrm{N}: \mathrm{C}$ (Figure S6) reflects the poor correlation between the nominal values of $\mathrm{H}: \mathrm{C}$ and $\mathrm{N}: \mathrm{C}$ within the PPRG sample set (Figure S7). The effects of heteroatoms on $\mathrm{D} 5 /(\mathrm{G}+\mathrm{D} 2)$ is a priori unexpected, as no major C-N bond is realistically expected within the $1100-1700 \mathrm{~cm}^{-1}$ spectral range. The excellent correlation with $\mathrm{H}: \mathrm{C}$, and not with $\mathrm{N}: \mathrm{C}$, further confirm the direct dependence of $\mathrm{D} 5 /(\mathrm{G}+\mathrm{D} 2)$ from $\mathrm{H}: \mathrm{C}$. 
By identifying a metric based on both the non-aromatic (D5 band) and aromatic/graphitic component ( $\mathrm{G}, \mathrm{D} 2$ bands), the evaluation of thermal maturity in OM (conventionally obtained in Raman - based indicators in terms of aromatic nanostructure, such as D1/G or $\left.\omega_{\mathrm{G}}\right)$ can be independently evaluated against its chemistry, using the Raman-derived $\mathrm{H}: \mathrm{C}$ content. This enables us, for example, to evaluate the role of nanostructure for different OM with similar H:C chemistry. Fig. S8 shows the spectra of the PPRG-048 (shale lithology, $2.5 \mathrm{Ga}$, Pilbara Craton, Hamersley Formation) and the PPRG-266 (shale lithology, $\sim 3.0 \mathrm{Ga}$, Mozaan Group), both having the same nominal H:C of 0.11. The differences are striking: PPRG-048 has significantly broader D1 and G peaks than PPRG-266, which shows the resolution of the D2 peak as a shoulder to the G peak. This, in addition to the sharper $\omega_{\mathrm{G}}$ and $\omega_{\mathrm{D} 1}$ for PPRG-266, suggests a nanostructure that exhibits the presence of spatially more extended graphitic clusters than PPRG-048, which appears to be more amorphous, despite having the same H:C. A similar trend can be observed in comparing two different coals with identical H:C (DECS-21 and DECS1515, Fig. S11). We stress that despite the striking spectral differences related to the nanostructure, the $\mathrm{D} 5 /(\mathrm{G}+\mathrm{D} 2)$ peak ratios are similar (More info and spectral fitting in supplementary information), reflecting the actual similarity in H:C. Future studies are needed to elucidate the nano-microstructural differences highlighted from the Raman spectra for a particular $\mathrm{H}: \mathrm{C}$ in relation to chemical (including heteroatoms such as $\mathrm{S}, \mathrm{O}$, $\mathrm{N}$ ) and biological origin of the organic matter (biological or abiotic), burial conditions (anisotropic stress affecting nucleation of aromatic clusters), catalytic effects induced by minerals and inorganics. 


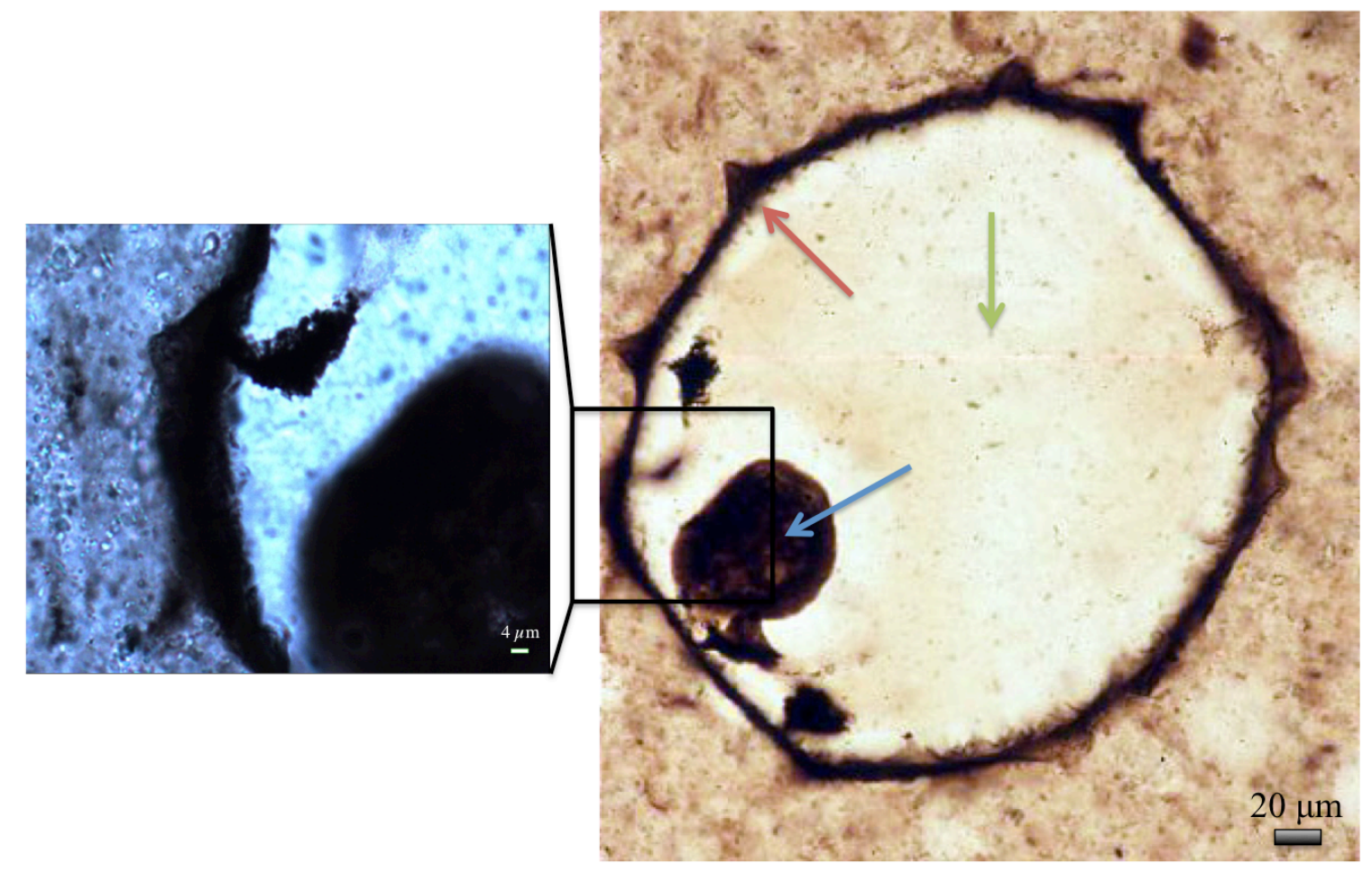

Figure 3 Optical micrographs of a fossil protist, Trachyhystrichosphaera aimika, from silicified coastal carbonates of the 750 Ma Draken Formation, Spitsbergen. Raman mapping is carried out at low magnification (10X, spatial resolution: $\sim 5 \mu \mathrm{m}$ ) over the full fossil (large image), and at high magnification (50X, spatial resolution: $\sim 1 \mu \mathrm{m}$ ) over the area within the white box, shown in the inset. Cell walls, collapsed cell contents, and quartz infilling cement are indicated by the red, blue and green arrows, respectively.

We purposely chose OM with very different biological origin (marine PPRG vs terrestrial plant Type III kerogen) and oxygen content (low in PPRG, high in Type III kerogen) to extract the correlations between $\mathrm{D} 5 /(\mathrm{G}+\mathrm{D} 2)$ and $(\mathrm{D} 4+\mathrm{D} 5) /(\mathrm{G}+\mathrm{D} 2)$ vs $\mathrm{H}: \mathrm{C}$, to further highlight the universality of this method across different types of OM (Fig. 2). This is a direct consequence of its reliance on spectral features that are uniquely related to the $\mathrm{H}: \mathrm{C}$ chemistry of molecular compounds (aromatic and non-aromatic) within the OM itself. Hence, evaluating the correct $\mathrm{H}: \mathrm{C}$ of $\mathrm{OM}$ is possible with the method here proposed, even in cases where high $\mathrm{H}$-containing species, such as the presence of traces of hydrated minerals as contaminants, cause conventional elemental analysis to overestimate $\mathrm{H}: \mathrm{C}$ [76]. For example, $\mathrm{OM}$ samples isolated from highly silicified samples via $\mathrm{HCl} / \mathrm{HF} / \mathrm{HCl}$ attack, often show anomalously high $\mathrm{H}: \mathrm{C}$ ratios attributable to secondary hydrated 
mineral contaminants. An example of the extent of such over-estimation is shown in Fig. S14 for the AIDP kerogens that were prepared as above but without additional kerogen purification steps. Here, a significant number of the analyzed samples display a nominal $\mathrm{H}: \mathrm{C}$ between 25 and $100 \%$ higher that measured using the $\mathrm{D} 5 /(\mathrm{G}+\mathrm{D} 2)$ ratio. The consequences for the systematic application of this method to OM in complex lithologies are far-reaching: it allows for the verification of OM preservation not only in terms of burial conditions, but also with respect to kerogen processing and isolation. It can be argued that kerogen isolation, required for $\mathrm{H}: \mathrm{C}$ elemental analysis, is in fact no longer needed for the method proposed here, so long as the Raman spectral signature of OM is significantly strong to be detected over fluorescence.

Potential uses for the elemental $\mathrm{H}: \mathrm{C}$ ratio data acquired in this way would be to rapidly and accurately discern the extent to which thermal metamorphism might have affected the preservation of hydrocarbon biomarkers [18]. Taken a step further, the elemental H:C ratios can be used to estimate and correct for positive shifts in the $\delta^{13} \mathrm{C}$ values of highly mature ancient kerogens, as has been observed by in several studies [15, 77-81]. A small sample of such calculations (Table S1) confirms that organic matter preserved in Archean sedimentary sequences is, on average, more ${ }^{13} \mathrm{C}$-depleted than that found in younger times consistent with other observations that the Archean carbon cycle must have operated in fundamentally different ways prior to and following the oxygenation of Earth's ocean-atmosphere system [14, 78, 82-84]. Furthermore, because kerogen isolation is unnecessary, this method may be applied directly to OM still embedded within its original host rock provided the organic domains are of sufficient size. In this context, microRaman spectroscopy could afford valuable augmentation for SIMS isotope analysis of organically-preserved fossils. Being non-destructive, samples could be first screened in this way to identify chemical differences at small spatial scales to prioritize regions for detailed SIMS measurements [85-87].

The preservation of OM within its inorganic framework favors investigation of the spatially resolved variability of $\mathrm{H}: \mathrm{C}$ through the $\mathrm{D} 5 /(\mathrm{G}+\mathrm{D} 2)$ Raman ratio, within a particular fossilized object or among several visibly or functionally different objects 
within the same rock. As an example, we analyzed the protistan microfossil Trachyhystrichosphaera aimika, preserved in silicified coastal carbonates of the ca. 750 Ma Draken Formation, Spitsbergen [88]. The OM in this ca. $300 \mu \mathrm{m}$ wide fossil occurs in a well preserved cell wall and collapsed cell contents within its interior (Fig. 3). Raman mapping on this fossil was recently performed to investigate the heterogeneity and potential biotic origin of the OM in organic fossil based on the evolution of structural order, rather then chemical composition [4-6]. With this work, we set to perform Raman mapping at different magnifications to quantitatively probe the relation of spectral sensitivity to differences in $\mathrm{H}: \mathrm{C}$ across the sample in relation to length-scale. At low magnification (10x, spatial resolution of $\sim 5 \mu \mathrm{m}$ ), the integrated intensity of the $\mathrm{G}$ peak mapped across the full fossil is shown in Fig. 4a. The absence of significant OM in the quartz core (green arrow, Fig. 3) is clearly highlighted by the almost negligible intensity of the $G$ peak in this material. Strong $G$ peak intensity is observed from the collapsed cytoplasm, the cell walls, and in the space probed outside the cell walls, which is pigmented by abundant particulate OM. Despite the strong presence of quartz outside the cell walls, residual organic matter is clearly detected. And despite the observation that $\mathrm{OM}$ is presented in morphologically distinct entities of differing relative abundance (from the strength of the G peak), there is little variability in the $\mathrm{H}: \mathrm{C}$ ratio that can be extracted from the intensity ratio $\mathrm{D} 5 /(\mathrm{G}+\mathrm{D} 2)$ (Fig. $4 \mathrm{~b})$. This is not unexpected, as thermal maturation at the micron-scale should lead to similar $\mathrm{H}: \mathrm{C}$ values during diagenesis. However, while strong differences are not expected, phase discrimination based on weak spectral differences in relation to $\mathrm{H}: \mathrm{C}$ and nanostructural ordering can be achieved using a statistical approach based on cluster analysis [40, 41] (Details in Methods and Supporting Information).

The approach followed in this study is based on mixture modeling and implements maximum likelihood estimation and Bayesian Information Criteria (BIC) to identify the most likely model and the number of clusters. Two complementary approaches are followed in defining the clustering parameters, in addition to the $\mathrm{H}: \mathrm{C}$ ratio and FWHM of the $\mathrm{G}$ peak, $\left.\omega_{\mathrm{G}}: 1\right)$ intensity peak ratios $(\mathrm{D} 1 /(\mathrm{G}+\mathrm{D} 2), \mathrm{D} 5 /(\mathrm{G}+\mathrm{D} 2),(\mathrm{D} 4+\mathrm{D} 5+\mathrm{D} 1) /(\mathrm{G}+\mathrm{D} 2)$, $(\mathrm{D} 4+\mathrm{D} 5) /(\mathrm{G}+\mathrm{D} 2))$ or 2) absolute intensities (D1, D4, D5, G+D2). 
Cluster identification based on peak intensity for the low resolution Raman map is shown in Fig. 4c-d. The quartz phase is clearly identified (phase 6) not from an actual spectral signature of quartz, but through the low intensity of the $G$ peak. The main organic phase (phase 5) includes both the cell walls and collapsed cell content. Residual OM outside the cell is either identified within the organic phase itself or within one of the remaining "hybrid" phases. If we focus on the OM within the cell (wall and content), we notice that no diversification is observed within the organic phase (phase 5) based on differences either in $\mathrm{H}: \mathrm{C}$ or nanostructural ordering. This would be intuitively expected, as peak intensities tend to reflect relative abundance rather than differences in comparing spectral features. We infer that cluster analysis based on peak intensity provides phase identification based on relative concentration of organic and inorganics within the region probed. We note that from a statistical perspective, the over-clustering with more phases than one would expect can provide a guideline whether similar phases can be combined, or whether the over-clustering allows for the identification of particular interfacial phases that in themselves may contain specific information about the interface (between different organics, or between inorganics/minerals and organics, etc). 

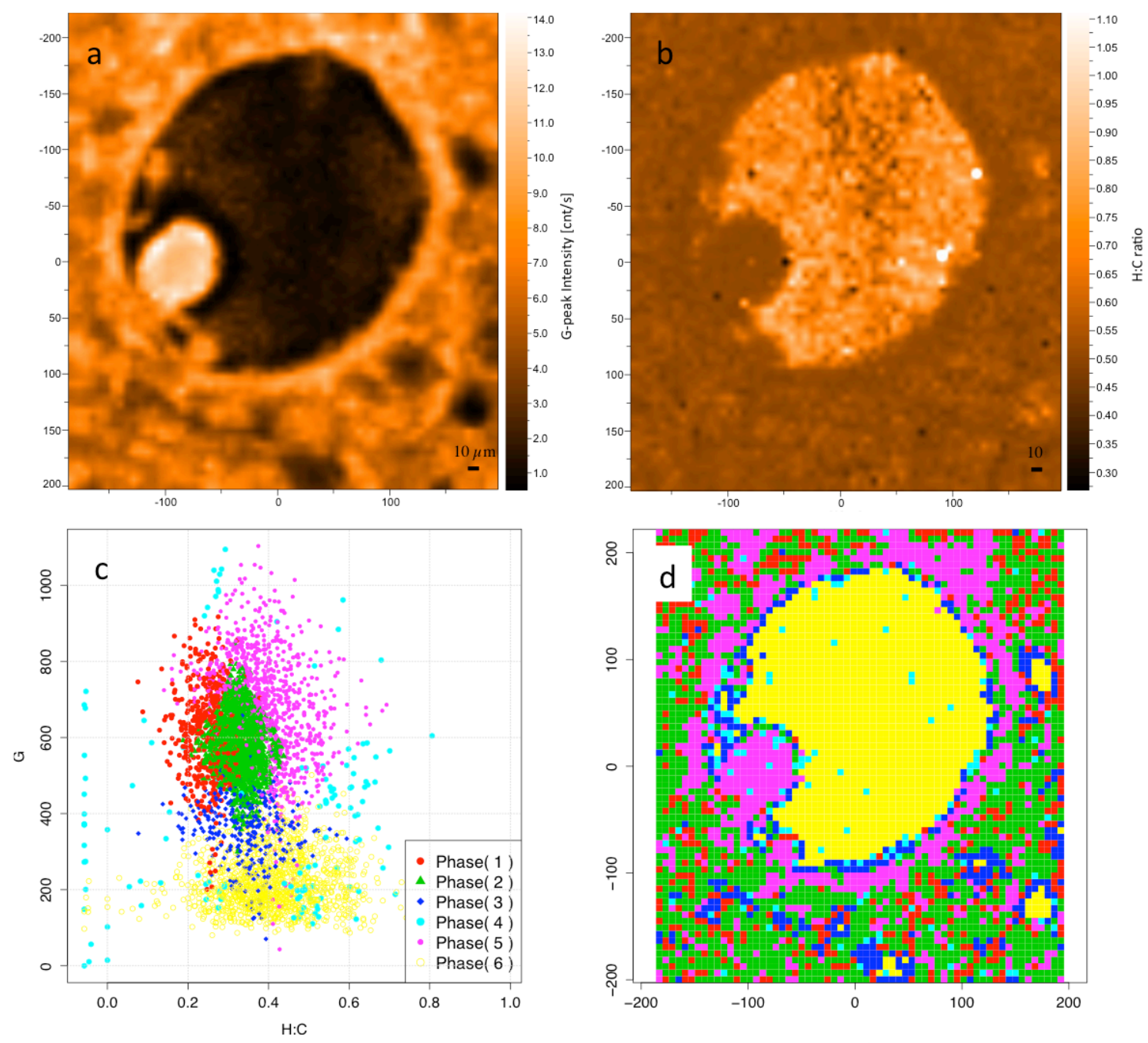

Figure 4 Low resolution Raman map (magnification 10x) of the protistan microfossil Trachyhystrichosphaera aimika. (a) Map of the integrated intensity of the G peak; (b) map of the H:C ratio extracted from the $\mathrm{D} 5 /(\mathrm{G}+\mathrm{D} 2)$ intensity peak ratio. Cluster analysis including intensity peak intensity (D1, D4, D5, G+D2) identifies 6 different phases. (c) The G peak intensity vs H:C is plotted to highlight the heterogeneity in $\mathrm{H}: \mathrm{C}$ in relation to a particular phase. We note that collapsed cell content (blue arrow in Fig. 3), has a higher average H:C than the cell walls (red arrow in Fig. 3) (d) The Raman map is plotted against the assigned detected phase. Phase 6 is the quartz core (green arrow in Fig. 3) within the cell walls. Phase 5 corresponds to the organic matter in the cell wall and collapsed cell content. 

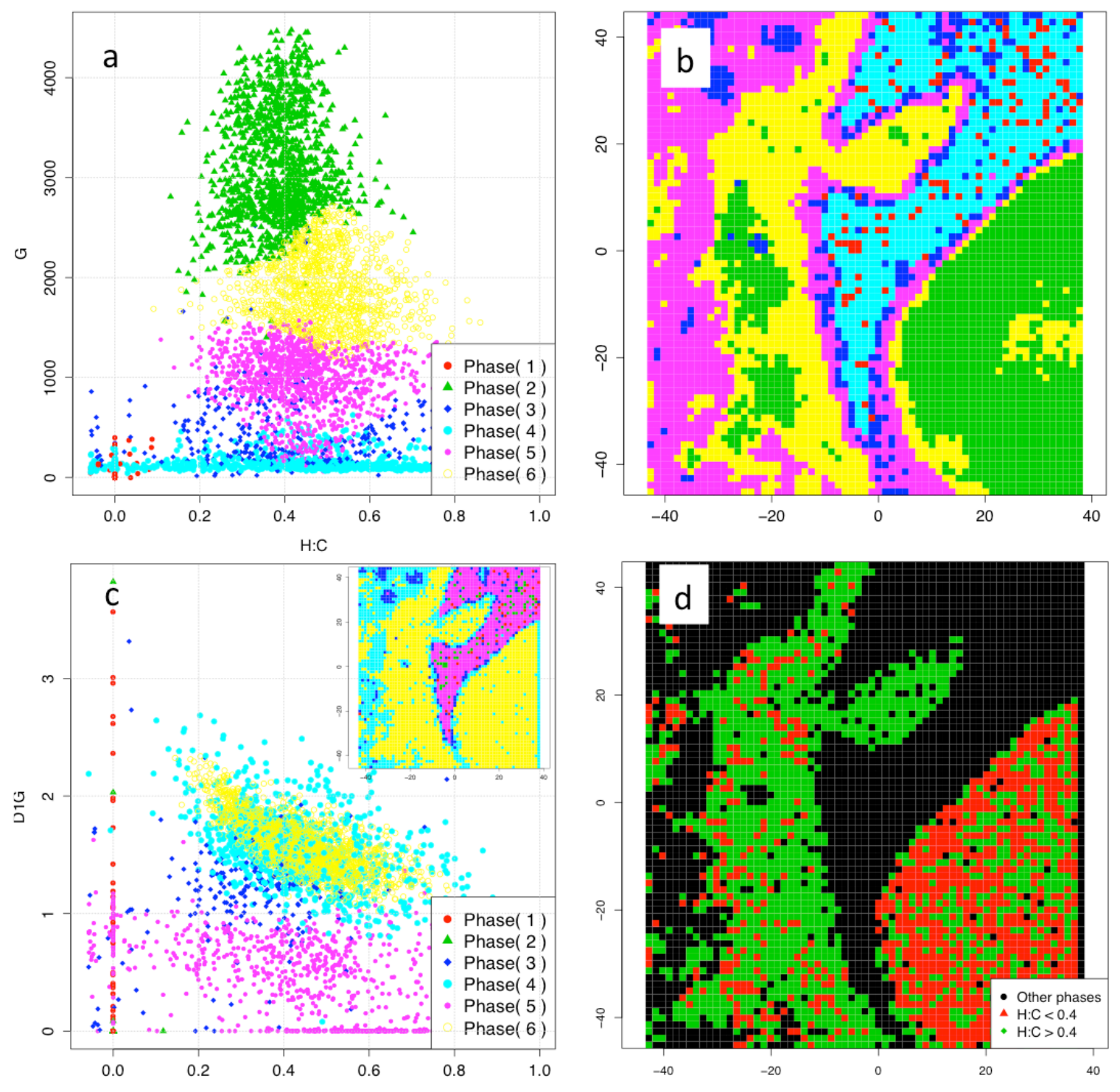

Figure 5 Cluster analysis of the high resolution Raman map (magnification 50x) of region of the organic fossil highlighted in the inset of Figure 3. (a-b) Cluster analysis including intensity peak intensity (D1, D4, D5, G) identifies 6 different phases. Phase 3 is the quartz core within the cell walls. Phases 2 and 6 correspond to the organic matter in the cell wall and collapsed cell content, respectively. (c) When cluster analysis is carried out based on peak intensity ratios (D5/(G+D2), D1/(G+D2), (D4+D5)/(G+D2), $(\mathrm{D} 4+\mathrm{D} 5+\mathrm{D} 1) /(\mathrm{G}+\mathrm{D} 2))$, the organic matter is detected as a single phase (6). Within this phase, however, a strong differentiation based on different average H:C, $0.33 \pm 0.07$ and $0.49 \pm 0.05$ for the cell content and wall respectively is observed (d).

The potential for more accurate spatially resolved analysis and possible phase discrimination within the organic matter is explored with a high resolution Raman map (Fig. 5a, magnification: 50X, spatial resolution $\sim 1 \mu \mathrm{m}$ ) corresponding the region of the 
organic fossil highlighted in Fig. 3. The intensity-based cluster analysis still correctly identifies the inorganic phase (Phase 4, cyan in Fig 5b-c). Two distinct phases are identified for the OM, from collapsed cell content and walls (phase 2 and 6, green and purple in Fig. 5b-c). The collapsed cell content is predominant in phase 2, while the cell wall is equally divided between the phase 2 and 6 . In addition to OM abundance, the distinction in two separate OM phases appears to be partially driven by differences in $\mathrm{H}: \mathrm{C}$, as reflected by the average $\mathrm{H}: \mathrm{C}$ ratios for the two phases $(0.38 \pm 0.10$ and $0.49 \pm 0.10$ for phase 2 and 6 respectively), with a threshold in $\mathrm{H}: \mathrm{C}$ between the two phases of about 0.4. The convolution between the distribution of $\mathrm{H}: \mathrm{C}$ ratios and difference in $\mathrm{OM}$ concentration limits phase identification based uniquely on $\mathrm{H}: \mathrm{C}$ within the OM. A clear example is given by the cell wall, which includes both phases despite having a fairly homogeneous H:C.

Cluster analysis based on peak intensity ratios removes the variability introduced by varying concentrations of OM, leaving only variability in $\mathrm{H}: \mathrm{C}$ (through D5/(G+D2)) and order in the aromatic nanostructure (D1/G). The results of the clustering based on peak intensity ratio are shown in Fig. 5c. The OM is identified as a unique phase (phase 6, yellow in Fig. 5c). Additional OM outside the cell walls is identified by phase 4 (cyan). The main organic phase 6 , appears to span a wide $\mathrm{H}: \mathrm{C}$ range from 0.2 to 0.7 . Such broad variability is only weakly reflected in the limited variability in D1/G (Fig. 5c), providing additional insight on the limited reliability of D1/G (associated with ordering and size of aromatic clusters) as a metric to assess chemical (rather than structural) variability in OM. In essence, the limited variability in $\mathrm{D} 1 / \mathrm{G}$ leaves $\mathrm{H}: \mathrm{C}$ as the only diversifier chemical composition. As a result, what appears to be a fairly continuous distribution of $\mathrm{H}: \mathrm{C}$ values in the $\mathrm{OM}$ (Fig. 5c) result in a single and chemically heterogeneous OM phase. Yet, when the previously identified threshold in $\mathrm{H}: \mathrm{C}(\sim 0.4)$ is introduced to the single OM phase (Fig. 5d), a striking differentiation in $\mathrm{H}: \mathrm{C}$ appears between the cell content and wall, based uniquely on original chemical differences between the two cellular constituents. A relation between structural and chemical diversity may still exists, since a similar differentiation in structural order was observed between cell content and cell walls [6]. We conclude that a significant chemical differentiation still exists between 
the cell walls and the collapsed cell content, that is, however, not reflected in a significant change in nanostructural ordering of the aromatic component. The general and sampleagnostic ability to compare independently the same parameter in different phases, shows that clustering analysis serve a unique opportunity in restricting the pool of parameters that contribute to a particular feature (for example $\mathrm{H}: \mathrm{C}$ ) and allows for evaluating the diversity of another parameter (for example D1/G and therefore the size of aromatics) within that specific phase.

In conclusion, a new quantitative, non-destructive and universal method to directly extract $\mathrm{H}: \mathrm{C}$ values from $\mathrm{OM}$ has been developed. This method allows for direct identification of the state of preservation of kerogen as a consequence of both burial and processing. Its reliance on spectral differences related to both aromatic and non-aromatic components in $\mathrm{OM}$ for the determination of $\mathrm{H}: \mathrm{C}$ enables the evaluation of maturity with respect to aromatic microstructural ordering, obtained through the D1/G. By extension, and benefitting from the non-invasive nature of Raman spectroscopy, chemical mapping is achieved in combination of statistical cluster analysis, with direct identification of spatially-resolved inorganic/organic phase detection. This methodology is directly applicable to the remote search for, and evaluation of, organic matter, geobiological studies of the early Earth, practical analyses of potential hydrocarbon reservoirs, or for the extraction of relevant optical and electronic parameters in all-carbon or OM-based electronic devices. Direct microRaman chemical mapping of microscopic fossils, or the preserved tissues of macroscopic fossils, or the determination of the chemical variability within electronic devices is also feasible.

Acknowledgements. N.F. gratefully acknowledges support by Shell Oil Company and Schlumberger through the X-Shale Consortium under the MIT-Energy Initiative, and Extramural Research by Shell Innovation Research and Development. R.E.S and E.D.M. acknowledge support from the Simons Foundation Collaboration on the Origins of Life. A.H.K and R.E.S. acknowledge support from the NASA Astrobiology Institute. C.H acknowledges support from the Max Planck Society. Pilbara clean drilling was generously supported by the Agouron Institute. 
Author contributions. N.F. and R.E.S. designed the research, analyzed data and wrote the paper with input from other authors; N.F. performed the research; E.D.M., A.H.K., C.H. provided samples and contributed to analysis of the data. 


\section{References}

[1] Keller BD, Ferralis N, Grossman JC. Rethinking Coal: Thin Films of Solution Processed Natural Carbon Nanoparticles for Electronic Devices. Nano Letters. 2016;16(5):2951-7.

[2] Colleary C, Dolocan A, Gardner J, Singh S, Wuttke M, Rabenstein R, et al. Chemical, experimental, and morphological evidence for diagenetically altered melanin in exceptionally preserved fossils. Proceedings of the National Academy of Sciences. 2015;112(41):12592-7.

[3] Wörmer L, Elvert M, Fuchser J, Lipp JS, Buttigieg PL, Zabel M, et al. Ultra-highresolution paleoenvironmental records via direct laser-based analysis of lipid biomarkers in sediment core samples. Proceedings of the National Academy of Sciences. 2014;111(44):15669-74.

[4] Foucher F, Ammar M-R, Westall F. Revealing the biotic origin of silicified Precambrian carbonaceous microstructures using Raman spectroscopic mapping, a potential method for the detection of microfossils on Mars. Journal of Raman Spectroscopy. 2015;46(10):873-9.

[5] Foucher F, Westall F. Raman Imaging of Metastable Opal in Carbonaceous Microfossils of the 700-800 Ma Old Draken Formation. Astrobiology. 2013;13(1):5767.

[6] Qu Y, Engdahl A, Zhu S, Vajda V, McLoughlin N. Ultrastructural Heterogeneity of Carbonaceous Material in Ancient Cherts: Investigating Biosignature Origin and Preservation. Astrobiology. 2015;15(10):825-42.

[7] Grotzinger JP, Sumner DY, Kah LC, Stack K, Gupta S, Edgar L, et al. A Habitable Fluvio-Lacustrine Environment at Yellowknife Bay, Gale Crater, Mars. Science. 2014;343(6169).

[8] Freissinet C, Glavin DP, Mahaffy PR, Miller KE, Eigenbrode JL, Summons RE, et al. Organic molecules in the Sheepbed Mudstone, Gale Crater, Mars. Journal of Geophysical Research: Planets. 2015;120:495-514.

[9] Biemann K, Oro J, Toulmin P, Orgel LE, Nier AO, Anderson DM, et al. The Search for Organic Substances and Inorganic Volatile Compounds in the Surface of Mars. J Geophys Res. 1977;82(28):4641-58.

[10] Biemann K, Oro J, Toulmin P, Orgel LE, Nier AO, Anderson DM, et al. Search for Organic and Volatile Inorganic Compounds in Two Surface Samples from the Chryse Planitia Region of Mars. Science. 1976;194(4260):72-6.

[11] Mahaffy PR, Webster CR, Cabane M, Conrad PG, Coll P, Atreya SK, et al. The Sample Analysis at Mars Investigation and Instrument Suite. Space Science Reviews. 2012;170(1-4):401-78.

[12] Ming DW, Archer PD, Glavin DP, Eigenbrode JL, Franz HB, Sutter B, et al. Volatile and Organic Compositions of Sedimentary Rocks in Yellowknife Bay, Gale Crater, Mars. Science. 2013;1245267Published online 9 December 2013 [DOI:10.1126/science.1245267].

[13] Brocks JJ, Logan GA, Buick R, Summons RE. Archean Molecular Fossils and the Early Rise of Eukaryotes. Science. 1999;285(5430):1033-6. 
[14] Fischer WW, Schroeder S, Lacassie JP, Beukes NJ, Goldberg T, Strauss H, et al. Isotopic constraints on the Late Archean carbon cycle from the Transvaal Supergroup along the western margin of the Kaapvaal Craton, South Africa. Precambrian Research. 2009;169(1-4):15-27.

[15] Hayes JM, Kaplan IR, Wedeking KW. Precambrian organic geochemistry: Preservation of the record. In: Schopf JW, ed. Earth 's Earliest Biosphere: Its Origin and Evolution. Princeton: Princeton Univ. Press 1983, p. 93-135.

[16] Brocks JJ, Buick R, Logan GA, Summons RE. Composition and syngeneity of molecular fossils from the 2.78 to 2.45 billion-year-old Mount Bruce Supergroup, Pilbara Craton, Western Australia. Geochimica et Cosmochimica Acta. 2003;67:4289-319.

[17] Oehler DZ, Cady S. Biogenicity and Syngeneity of Organic Matter in Ancient Sedimentary Rocks: Recent Advances in the Search for Evidence of Past Life. Challenges. 2014;5(2):260-83.

[18] French KL, Hallmann C, Hope JM, Schoon PL, Zumberge JA, Hoshino Y, et al. Reappraisal of hydrocarbon biomarkers in Archean rocks. Proceedings of the National Academy of Sciences. 2015;112(19):5915-20.

[19] Lewan MD, Buchardt B. Irradiation of organic matter by uranium decay in the Alum Shale, Sweden. Geochimica et Cosmochimica Acta. 1989;53(6):1307-22.

[20] Collins L, Tselev A, Jesse S, Okatan MB, Proksch R, Mathews JP, et al. Breaking the limits of structural and mechanical imaging of the heterogeneous structure of coal macerals. Nanotechnology. 2014;25(43):435402.

[21] Czaja AD, Kudryavtsev AB, Cody GD, Schopf JW. Characterization of permineralized kerogen from an Eocene fossil fern. Organic Geochemistry. 2009;40(3):353-64.

[22] Marshall CP, Javaux EJ, Knoll AH, Walter MR. Combined micro-Fourier transform infrared (FTIR) spectroscopy and micro-Raman spectroscopy of Proterozoic acritarchs: A new approach to Palaeobiology. Precambrian Research. 2005;138(3-4):208-24.

[23] Wopenka B. Raman observations on individual interplanetary dust particles. Earth and Planetary Science Letters. 1988;88(3-4):221-31.

[24] Quirico E, Borg J, Raynal P-I, Montagnac G, d'Hendecourt L. A micro-Raman survey of 10 IDPs and 6 carbonaceous chondrites. Planetary and Space Science. 2005;53(14-15):1443-8.

[25] Ueno Y, Isozaki Y, Yurimoto H, Maruyama S. Carbon Isotopic Signatures of Individual Archean Microfossils(?) from Western Australia. International Geology Review. 2001;43(3):196-212.

[26] Schopf JW, Kudryavtsev AB, Agresti DG, Wdowiak TJ, Czaja AD. Laser-Raman imagery of Earth's earliest fossils. Nature. 2002;416(6876):73-6.

[27] Kudryavtsev AB, Schopf JW, Agresti DG, Wdowiak TJ. In situ laser-Raman imagery of Precambrian microscopic fossils. Proceedings of the National Academy of Sciences. 2001;98(3):823-6.

[28] Steele A, McCubbin FM, Fries M, Kater L, Boctor NZ, Fogel ML, et al. A Reduced Organic Carbon Component in Martian Basalts. Science. 2012;337(6091):212-5. 
[29] Beyssac O, Goffé B, Petitet J-P, Froigneux E, Moreau M, Rouzaud J-N. On the characterization of disordered and heterogeneous carbonaceous materials by Raman spectroscopy. Spectrochimica Acta Part A: Molecular and Biomolecular Spectroscopy. 2003;59(10):2267-76.

[30] Beyssac 0, Rouzaud J-N, Goffé B, Brunet F, Chopin C. Graphitization in a highpressure, low-temperature metamorphic gradient: a Raman microspectroscopy and HRTEM study. Contrib Mineral Petrol. 2002;143(1):19-31.

[31] Lahfid A, Beyssac O, Deville E, Negro F, Chopin C, Goffé B. Evolution of the Raman spectrum of carbonaceous material in low-grade metasediments of the Glarus Alps (Switzerland). Terra Nova. 2010;22(5):354-60.

[32] Bower DM, Steele A, Fries MD, Kater L. Micro Raman Spectroscopy of Carbonaceous Material in Microfossils and Meteorites: Improving a Method for Life Detection. Astrobiology. 2012;13(1):103-13.

[33] Sforna MC, van Zuilen MA, Philippot P. Structural characterization by Raman hyperspectral mapping of organic carbon in the 3.46 billion-year-old Apex chert, Western Australia. Geochimica et Cosmochimica Acta. 2014;124:18-33.

[34] Jehlička J, Bény C. Application of Raman microspectrometry in the study of structural changes in Precambrian kerogens during regional metamorphism. Organic Geochemistry. 1992;18(2):211-3.

[35] Schopf JW, Kudryavtsev AB, Agresti DG, Czaja AD, Wdowiak TJ. Raman Imagery: A New Approach to Assess the Geochemical Maturity and Biogenicity of Permineralized Precambrian Fossils. Astrobiology. 2005;5(3):333-71.

[36] Heredia-Guerrero JA, Benítez JJ, Domínguez E, Bayer I, Cingolani R, Athanassiou A, et al. Infrared and Raman spectroscopic features of plant cuticles: A review. Frontiers in Plant Science. 2014;5.

[37] Marshall CP, Love GD, Snape CE, Hill AC, Allwood AC, Walter MR, et al. Structural characterization of kerogen in $3.4+$ Ga Archaean cherts from the Pilbara Craton, Western Australia. Precambrian Research. 2007;155(1-2):1-23.

[38] Risplendi F, Bernardi M, Cicero G, Grossman JC. Structure-property relations in amorphous carbon for photovoltaics. Applied Physics Letters.

2014;105(4):043903.

[39] Fraley C, Raftery AE. Model-Based Clustering, Discriminant Analysis, and Density Estimation. Journal of the American Statistical Association.

2002;97(458):611-31.

[40] Fraley C, Raftery AE. MCLUST: Software for Model-Based Cluster Analysis. J of Classification. 1999;16(2):297-306.

[41] Fraley C, Raftery AE. Model-based methods of classification: using the mclust software in chemometrics. Journal of Statistical Software. 2007;18: 1-13.

[42] Walter MR, Hofmann HJ, Schopf JW. Apendix 1; Geographic and geologic data for processed samples. In: Schopf JW, ed. Earth's earliest biosphere. Princeton, N.J.: Princeton University Pres 1983, p. 385-414.

[43] Anbar AD, Duan Y, Lyons TW, Arnold GL, Kendall B, Creaser RA, et al. A Whiff of Oxygen Before the Great Oxidation Event? Science. 2007;317(5846):1903-6.

[44] Buick R, Anbar AD, Mojzsis SJ, Kaufman AJ, Kieft TL, Lyons TW, et al. The case for scientific drilling of Precambrian sedimentary sequences: A mission to early Earth. American Geophysical Union, Fall Meeting 2001, abstract \#P22B-0544. 2004. 
[45] Beukes NJ, Evans DAD, Grotzinger JP, Kirschvink JL, Knoll AH, Sumner DY. Multidisciplinary Study Of The Precambrian Biosphere And Surficial Oxygenation, Kaapvaal Craton, South Africa: The Agouron Cores. International Journal of Astrobiology, Supplement. 2004;15.

[46] Waldbauer JR, Sherman LS, Sumner DY, Summons RE. Late Archean molecular fossils from the Transvaal Supergroup record the antiquity of microbial diversity and aerobiosis. Precambrian Research. 2009;169:28-47.

[47] Simonson BM, Sumner DY, Beukes NJ, Johnson S, Gutzmer J. Correlating multiple Neoarchean-Paleoproterozoic impact spherule layers between South Africa and Western Australia. Precambrian Research. 2009;169(1-4):100-11.

[48] Knoll AH, Beukes NJ. Introduction: Initial investigations of a Neoarchean shelf margin-basin transition (Transvaal Supergroup, South Africa). Precambrian Research. 2009;169(1-4):1-14.

[49] Ferrari AC, Robertson J. Interpretation of Raman spectra of disordered and amorphous carbon. Physical Review B. 2000;61(20):14095-107.

[50] Schopf JW, ed. Earth's earliest biosphere: Its origin and evolution. Princeton, NJ: Princeton University Press 1983.

[51] Malard LM, Pimenta MA, Dresselhaus G, Dresselhaus MS. Raman spectroscopy in graphene. Physics Reports. 2009;473(5-6):51-87.

[52] Kouketsu Y, Mizukami T, Mori H, Endo S, Aoya M, Hara H, et al. A new approach to develop the Raman carbonaceous material geothermometer for lowgrade metamorphism using peak width. Island Arc. 2014;23(1):33-50.

[53] Bouhadda Y, Bormann D, Sheu E, Bendedouch D, Krallafa A, Daaou M. Characterization of Algerian Hassi-Messaoud asphaltene structure using Raman spectrometry and X-ray diffraction. Fuel. 2007;86(12-13):1855-64.

[54] Sadezky A, Muckenhuber H, Grothe H, Niessner R, Pöschl U. Raman microspectroscopy of soot and related carbonaceous materials: Spectral analysis and structural information. Carbon. 2005;43(8):1731-42.

[55] Li X, Hayashi J-i, Li C-Z. FT-Raman spectroscopic study of the evolution of char structure during the pyrolysis of a Victorian brown coal. Fuel. 2006;85(1213):1700-7.

[56] Tuinstra F, Koenig JL. Raman Spectrum of Graphite. The Journal of Chemical Physics. 1970;53:1126-30.

[57] Pimenta MA, Dresselhaus G, Dresselhaus MS, Cancado LG, Jorio A, Saito R. Studying disorder in graphite-based systems by Raman spectroscopy. Physical Chemistry Chemical Physics. 2007;9(11):1276-90.

[58] Martins Ferreira EH, Moutinho MVO, Stavale F, Lucchese MM, Capaz RB, Achete CA, et al. Evolution of the Raman spectra from single-, few-, and many-layer graphene with increasing disorder. Physical Review B. 2010;82(12):125429. [59] Beyssac O, Goffé B, Chopin C, Rouzaud JN. Raman spectra of carbonaceous material in metasediments: a new geothermometer. Journal of Metamorphic Geology. 2002;20(9):859-71.

[60] Tissot BP, Welte DH. Petroleum formation and occurrence: a new approach to oil and gas exploration; 1978.

[61] Harris LV, Hutchinson IB, Ingley R, Marshall CP, Olcott Marshall A, Edwards HGM. Selection of Portable Spectrometers for Planetary Exploration: A Comparison 
of $532 \mathrm{~nm}$ and $785 \mathrm{~nm}$ Raman Spectroscopy of Reduced Carbon in Archean Cherts. Astrobiology. 2015;15(6):420-9.

[62] Ferralis N, Liu Y, Bake KD, Pomerantz AE, Grossman JC. Direct correlation between aromatization of carbon-rich organic matter and its visible electronic absorption edge. Carbon. 2015;88:139-47.

[63] Koyama Y, Ikeda K-i. Raman spectra and conformations of the cisunsaturated fatty-acid chains. Chemistry and Physics of Lipids. 1980;26(2):149-72. [64] De Gelder J, De Gussem K, Vandenabeele P, Moens L. Reference database of Raman spectra of biological molecules. Journal of Raman Spectroscopy. 2007;38(9):1133-47.

[65] Kuzmany H, Pfeiffer R, Salk N, Günther B. The mystery of the $1140 \mathrm{~cm}-1$ Raman line in nanocrystalline diamond films. Carbon. 2004;42(5-6):911-7.

[66] Ferrari AC, Robertson J. Resonant Raman spectroscopy of disordered, amorphous, and diamondlike carbon. Physical Review B. 2001;64(7):075414. [67] Frank CJ, McCreery RL, Redd DCB. Raman Spectroscopy of Normal and Diseased Human Breast Tissues. Analytical Chemistry. 1995;67(5):777-83. [68] Afseth NK, Wold JP, Segtnan VH. The potential of Raman spectroscopy for characterisation of the fatty acid unsaturation of salmon. Analytica Chimica Acta. 2006;572(1):85-92.

[69] Baeten V, Hourant P, Morales MT, Aparicio R. Oil and Fat Classification by FTRaman Spectroscopy. Journal of Agricultural and Food Chemistry. 1998;46(7):263846.

[70] Olsen EF, Rukke E-0, Flåtten A, Isaksson T. Quantitative determination of saturated-, monounsaturated- and polyunsaturated fatty acids in pork adipose tissue with non-destructive Raman spectroscopy. Meat Science. 2007;76(4):628-34.

[71] Dong W, Zhang Y, Zhang B, Wang X. Rapid prediction of fatty acid composition of vegetable oil by Raman spectroscopy coupled with least squares support vector machines. Journal of Raman Spectroscopy. 2013;44(12):1739-45. [72] Mayo DW, Miller FA, Hannah RW. Course Notes on the Interpretation of Infrared and Raman Spectra: John Wiley \& Sons, Inc.; 2003.

[73] Long DA. Raman spectroscopy: McGraw-Hill; 1977.

[74] Ferrari AC. Raman spectroscopy of graphene and graphite: Disorder, electron-phonon coupling, doping and nonadiabatic effects. Solid State Communications. 2007;143(1-2):47-57.

[75] Beegle L, Bhartia R, White M, DeFlores L, Abbey W, Yen-Hung W, et al. SHERLOC: Scanning habitable environments with Raman \&amp; luminescence for organics \&amp; chemicals. Aerospace Conference, 2015 IEEE; p. 1-11.

[76] Durand B, ed. Kerogen, Insoluble Organic Matter from Sedimentary Rocks. Paris: Editions Technip 1980.

[77] Des Marais DJ. Isotopic Evolution of the Biogeochemical Carbon Cycle During the Precambrian. Reviews in Mineralogy and Geochemistry. 2001;43(1):555-78.

[78] Des Marais DJ, Strauss H, Summons RE, Hayes JM. Carbon isotope evidence for the stepwise oxidation of the Proterozoic environment. Nature.

1992;359(6396):605-9. 
[79] McKirdy DM, Powell TG. Metamorphic Alteration of Carbon Isotopic Composition in Ancient Sedimentary Organic Matter: New Evidence from Australia and South Africa. Geology. 1974;2(12):591-5.

[80] Hoefs J, Frey M. The isotopic composition of carbonaceous matter in a metamorphic profile from the Swiss Alps. Geochimica et Cosmochimica Acta. 1976;40(8):945-51.

[81] Oehler DZ, Smith JW. Isotopic composition of reduced and oxidized carbon in early Archaean rocks from Isua, Greenland. Precambrian Research. 1977;5(3):2218.

[82] Hayes JM. Global methanotrophy at the Archean-Proterozoic transition. In: Bengston S, ed. Early Life on Earth (Nobel Symposium). New York Columbia University Press 1994, p. 200-36.

[83] Hayes JM, Waldbauer JR. The carbon cycle and associated redox processes through time. Philosophical Transactions of the Royal Society B: Biological Sciences. 2006;361(1470):931-50.

[84] Hayes JM. Geochemical evidence bearing on the origin of aerobiosis, a speculative hypothesis. In: Schopf JW, ed. Earth's earliest biosphere: Its origin and evolution. Princeton, NJ: Princeton University Press 1983, p. 291-301.

[85] Lepot K, Williford KH, Ushikubo T, Sugitani K, Mimura K, Spicuzza MJ, et al. Texture-specific isotopic compositions in $3.4 \mathrm{Gyr}$ old organic matter support selective preservation in cell-like structures. Geochimica et Cosmochimica Acta. 2013;112:66-86.

[86] Williford KH, Ushikubo T, Lepot K, Kitajima K, Hallmann C, Spicuzza MJ, et al. Carbon and sulfur isotopic signatures of ancient life and environment at the microbial scale: Neoarchean shales and carbonates. Geobiology. 2015:n/a-n/a. [87] Williford KH, Ushikubo T, Schopf JW, Lepot K, Kitajima K, Valley JW. Preservation and detection of microstructural and taxonomic correlations in the carbon isotopic compositions of individual Precambrian microfossils. Geochimica et Cosmochimica Acta. 2013;104(0):165-82.

[88] Knoll AH, Swett K, Mark J. Paleobiology Of A Neoproterozoic Tidal Flat Lagoonal Complex - The Draken Conglomerate Formation, Spitsbergen. Journal of Paleontology. 1991;65(4):531-70. 


\section{Supplementary Information}

\section{Rapid, direct and non-destructive assessment of fossil organic matter via microRaman spectroscopy}

Nicola Ferralis' Emily D. Matys, Andrew H. Knoll, Christian Hallmann, Roger E. Summons

\section{S1. Kerogen selection and isolation}

For the 16 samples (age range: 1.4-3.9 Gy) from the Precambrian Paleobiology Research Group (PPRG) [2], kerogens with a range of lithologies (shale, carbonate, chert etc) were isolated using standard acid attack methods, further demineralized by digestion with $\mathrm{AlCl}_{3}$ and $\mathrm{LiAlH}_{4}$ and checked by XRD to ensure neo-formed fluorides and pyrite were removed $[3,4]$. For the resulting isolated kerogens, $\mathrm{H}: \mathrm{C}$ ranged between 0.01 and 0.65 obtained by elemental analysis (Table S1) with excellent reproducibility.

For the Raman measurements, powder samples were dispersed on microscope slides.

\begin{tabular}{|c|c|c|c|c|c|c|c|c|c|c|}
\hline Sample ID & Age & Nominal H/C & Nominal N/C & D5/G & $\mathrm{H}: \mathrm{C}-(\mathrm{D} 5 / \mathrm{G})$ & $(\mathrm{D} 4+\mathrm{D} 5) / \mathrm{G}$ & $\mathrm{H}: \mathrm{C}-(\mathrm{D} 4+\mathrm{D} 5) / \mathrm{G}$ & $d^{13} c$ & Orig. $d^{13} c$ & Reference \\
\hline PPRG-038 & $\sim 2.7$ & 0.14 & 0.004 & 0.204 & 0.13 & 0.402 & 0.17 & -41.2 & -44.1 & 6,61 \\
\hline PPRG-048 & $\sim 2.5$ & 0.11 & 0.008 & 0.133 & 0.06 & 0.344 & 0.14 & -32.4 & -35.9 & $"$ \\
\hline PPRG-060 & $\sim_{2}$ & 0.32 & 0.005 & 0.412 & 0.31 & 0.641 & 0.32 & -29.3 & -30.8 & $"$ \\
\hline PPRG-113 & $\sim 1.64$ & 0.39 & 0.013 & 0.532 & 0.41 & 0.860 & 0.45 & -38.9 & -39.8 & $"$ \\
\hline PPRG-154 & $\sim 1.6$ & 0.39 & 0.022 & 0.525 & 0.41 & 0.838 & 0.43 & -30.7 & -31.7 & $"$ \\
\hline PPRG-155 & $\sim 1.6$ & 0.45 & 0.015 & 0.552 & 0.43 & 0.874 & 0.46 & -33.5 & -34.4 & $"$ \\
\hline PPRG-181 & $\sim 3.5$ & 0.12 & 0.001 & 0.200 & 0.12 & 0.300 & 0.11 & -15.4 & -18.3 & $"$ \\
\hline PPRG-254 & $\sim 2.6$ & 0.10 & 0.008 & 0.142 & 0.07 & 0.279 & 0.10 & -31.2 & -34.6 & $"$ \\
\hline PPRG-266 & $\sim 3.0$ & 0.11 & 0.003 & 0.197 & 0.12 & 0.246 & 0.08 & -27.3 & -30.2 & $"$ \\
\hline PPRG-304 & $\sim 2.2$ & 0.20 & 0.007 & 0.306 & 0.22 & 0.557 & 0.27 & -32.5 & -34.6 & $"$ \\
\hline PPRG-325 & $\sim 2.6$ & 0.17 & 0.009 & 0.264 & 0.18 & 0.418 & 0.18 & -27.2 & -29.6 & $"$ \\
\hline PPRG -440 & $\sim 1.8$ & 0.27 & 0.005 & 0.382 & 0.28 & 0.715 & 0.36 & -33.2 & -34.9 & $"$ \\
\hline PPRG-465 & $\sim 3.9$ & 0.02 & 0.001 & 0.111 & 0.05 & 0.104 & 0.00 & -10.0 & -13.7 & $"$ \\
\hline PPRG-466 & $\sim 3.8$ & 0.01 & 0.001 & 0.096 & 0.03 & 0.090 & 0.00 & -13.2 & -17.0 & $"$ \\
\hline PPRG-498 & $\sim 1.8$ & 0.40 & 0.012 & 0.526 & 0.41 & 0.811 & 0.42 & -32.1 & -33.1 & $"$ \\
\hline DECS-21 & L. Penn. & 0.53 & & 0.683 & 0.54 & 0.886 & 0.46 & ND & ND & $68-70$ \\
\hline DECS-1515 & L. Penn. & 0.53 & & 0.655 & 0.52 & 0.891 & 0.47 & ND & ND & " \\
\hline ARG-8 & L. Penn. & 0.59 & & 0.713 & 0.57 & 1.043 & 0.56 & ND & ND & $"$ \\
\hline DECS-19 & L. Penn. & 0.65 & & 0.805 & 0.65 & 1.166 & 0.63 & ND & ND & $"$ \\
\hline AIDP $2116.09 \mathrm{~m}$ & $\sim 2.6$ & 0.62 & & 0.463 & 0.35 & 0.702 & 0.35 & -43.1 & -44.3 & 9 \\
\hline AIDP $2146.20 \mathrm{~m}$ & $\sim 2.6$ & 0.37 & & 0.325 & 0.23 & 0.539 & 0.25 & -43.3 & -45.3 & " \\
\hline AIDP $2197.2 \mathrm{~m}$ & $\sim 2.6$ & 0.71 & & 0.366 & 0.27 & 0.611 & 0.30 & -49.9 & -51.6 & $"$ \\
\hline AIDP $2291.28 \mathrm{~m}$ & $\sim 2.6$ & 0.30 & & 0.470 & 0.36 & 0.754 & 0.38 & -48.8 & -50.0 & $"$ \\
\hline AIDP $2301.40 \mathrm{~m}$ & $\sim 2.6$ & 0.67 & & 0.498 & 0.38 & 0.757 & 0.39 & -42.2 & -43.3 & $"$ \\
\hline AIDP $2322.82 \mathrm{~m}$ & $\sim 2.6$ & 0.25 & & 0.443 & 0.33 & 0.692 & 0.35 & -43.6 & -44.9 & $"$ \\
\hline AIDP $2327.42 \mathrm{~m}$ & $\sim 2.6$ & 0.34 & & 0.442 & 0.33 & 0.777 & 0.40 & -44.4 & -45.7 & $"$ \\
\hline AIDP $2325.48 \mathrm{~m}$ & $\sim 2.6$ & 0.45 & & 0.333 & 0.24 & 0.564 & 0.27 & -44.8 & -46.7 & $"$ \\
\hline AIDP $398.36 \mathrm{~m}$ & $\sim 2.6$ & 0.90 & & 0.638 & 0.50 & 0.824 & 0.43 & -42.0 & -42.6 & $"$ \\
\hline AIDP $3130.30 \mathrm{~m}$ & $\sim 2.6$ & 0.40 & & 0.498 & 0.38 & 0.808 & 0.42 & -41.9 & -43.0 & $"$ \\
\hline GKP $173.4 \mathrm{~m}$ & Permian & 7.57 & & 0.351 & 0.26 & 0.579 & 0.28 & -28.8 & -30.6 & 64 \\
\hline GKP $678.2 \mathrm{~m}$ & $\sim 2.6$ & 0.56 & & 0.195 & 0.12 & 0.275 & 0.10 & -27.5 & -30.4 & $"$ \\
\hline GKP $1248.9 m$ & 2.7 & 0.61 & & 0.223 & 0.14 & 0.348 & 0.14 & -38.0 & -40.7 & $"$ \\
\hline GKF $178.5 \mathrm{~m}$ & Permian & 6.67 & & 0.320 & 0.23 & 0.496 & 0.23 & -24.0 & -26.0 & $"$ \\
\hline GKF $508.2 \mathrm{~m}$ & 2.5 & 0.27 & & 0.258 & 0.17 & 0.377 & 0.16 & ND & ND & $"$ \\
\hline GKF $1435.0 \mathrm{~m}$ & $\sim 2.65$ & 0.61 & & 0.212 & 0.13 & 0.349 & 0.14 & -36.8 & -46.9 & $"$ \\
\hline
\end{tabular}




\begin{tabular}{|c|c|c|c|c|c|}
\hline Sample ID & Lithology & Stratigraphic Unit & Tectonic Unit & Craton/Locat. & Reference \\
\hline PPRG-038 & shale & Jeerinah Fm. & Fortescue & Pilbara & 6,61 \\
\hline PPRG-048 & shale & Mt. McRae Fm. & Hamerlsley & Pilbara & $"$ \\
\hline PPRG-060 & carbonate & Duck Creek Fm. & Wyloo & W. Australia & $"$ \\
\hline PPRG-113 & carbonate/chert/shale & HYC Pyritic Shale Mbr. & McArthur & N.T. Australia & $"$ \\
\hline PPRG-154 & dolomitic/chert & Bungle Bungle Dolomite & Birrindudu & W. Australia & $"$ \\
\hline PPRG-155 & shale & Bungle Bungle Dolomite & Birrindudu & W. Australia & $"$ \\
\hline PPRG-181 & cherty shale & Theepruit Fm. & Barberton & S. Africa & $"$ \\
\hline PPRG-254 & carbonate & Huntsman Limestone & Bulawayan & S. Africa & " \\
\hline PPRG-266 & stromatolitic dolomite & Pongola Supergroup & Wit Mfolozi Inlier & S. Africa & $"$ \\
\hline PPRG-304 & stromatolitic dolomite & Malmani Supergroup & Transvaal & Kaapvaal & $"$ \\
\hline PPRG-325 & chert & Steeprock Group & Wabigoon Belt & Ontario, Canada & $"$ \\
\hline PPRG-440 & cherty carbonate & Earaheedy Group & Nabberu & W. Australia & " \\
\hline PPRG-465 & schist & Isua Supracrustal Sequence' & Isua Supracrustal & E. Greenland & $"$ \\
\hline PPRG-466 & schist & Isua Supracrustal Sequence' & Isua Supracrustal & E. Greenland & $"$ \\
\hline PPRG-498 & shale & Rove Fm. & Port Arthur & Ontario, Canada & $"$ \\
\hline DECS-21 & coal VRo 5.19 & Lykens Valley, Columbia & Appalachian & PA, USA & $68-70$ \\
\hline DECS-1515 & coal VRo 2.8 & PA Semian, Sullivan, PA & Appalachian & PA, USA & $"$ \\
\hline ARG-8 & coal VRo 1.68 & Pocahontas & Appalachian & VA, USA & $"$ \\
\hline DECS-19 & coal VRo 1.71 & Pocahontas No.3, Buchanan, VA & Appalachian & VA, USA & $"$ \\
\hline AIDP $2116.09 \mathrm{~m}$ & fine-grained dolarenite & Carawine $\mathrm{Fm}$. & Fortescue & Pilbara & 9 \\
\hline AIDP $2146.20 \mathrm{~m}$ & fine-grained dolarenite & Carawine Fm. & Fortescue & Pilbara & $"$ \\
\hline AIDP $2197.2 \mathrm{~m}$ & fine-grained dolarenite & Carawine Fm. & Fortescue & Pilbara & $"$ \\
\hline AIDP $2291.28 \mathrm{~m}$ & marly mudstone & Jeerinah Fm. & Fortescue & Pilbara & $"$ \\
\hline AIDP $2301.40 \mathrm{~m}$ & black kerogenous shale & Jeerinah Fm. & Fortescue & Pilbara & $"$ \\
\hline AIDP $2322.82 \mathrm{~m}$ & black kerogenous shale & Jeerinah Fm. & Fortescue & Pilbara & $"$ \\
\hline AIDP $2327.42 m$ & black kerogenous shale & Jeerinah $\mathrm{Fm}$. & Fortescue & Pilbara & $"$ \\
\hline AIDP $2325.48 \mathrm{~m}$ & black kerogenous shale & Jeerinah Fm. & Fortescue & Pilbara & $"$ \\
\hline AIDP $398.36 \mathrm{~m}$ & black kerogenous shale & Jeerinah Fm. & Fortescue & Pilbara & $"$ \\
\hline AIDP $3130.30 \mathrm{~m}$ & black kerogenous shale & Jeerinah Fm. & Fortescue & Pilbara & $"$ \\
\hline GKP $173.4 \mathrm{~m}$ & diamictite & Dwyka Fm. & Dwyka Basin & southern Africa & 64 \\
\hline GKP $678.2 \mathrm{~m}$ & kerogenous carbonate & Kamden Member & Transvaal & Kaapvaal & $"$ \\
\hline GKP $1248.9 m$ & pyritic carbonate & Vryburg Fm. & Transvaal & Kaapvaal & $"$ \\
\hline GKF $178.5 \mathrm{~m}$ & diamictite & Dwyka Fm. & Dwyka Basin & southern Africa & $"$ \\
\hline GKF $508.2 \mathrm{~m}$ & pyritic shale & Nauga Fm. & Transvaal & Kaapvaal & $"$ \\
\hline GKF $1435.0 \mathrm{~m}$ & pyritic shale & Lokammonna Fm. & Transvaal & Kaapvaal & $"$ \\
\hline
\end{tabular}

Table S1. Sample pedigrees for kerogens studied in this report. C-isotopic data for Archean and Proterozoic kerogens were corrected for the fractionation resulting from thermal alteration using the polynomial equation 3 from [1]. The naming convention for each class is listed as follow: PPRG (Precambrian Paleobiology Research Group); DECS (Department of Energy Coal Samples); ARG (Argonne Coal Bank); AIDP (Agouron Institute Drilling Projects, Australia); GKF-GKP (Agouron Institute Drilling Projects, South Africa).

\begin{tabular}{|c|c|c|c|c|c|c|c|}
\hline \multicolumn{7}{|c|}{ Type III Kerogen } \\
\hline DOE ID & Seam & Location & Rank & $\begin{array}{c}\text { C- } \\
\text { content } \\
{[\%]}\end{array}$ & $\begin{array}{c}\text { Mean } \\
\text { VRo } \\
{[\%]}\end{array}$ & H:C & O:C \\
\hline DECS21 & $\begin{array}{c}\text { Lykens } \\
\text { Valley 2 }\end{array}$ & $\begin{array}{c}\text { Columbia, } \\
\text { PA }\end{array}$ & an & 82.6 & 5.19 & 0.533 & 0.03 \\
\hline DECS1515 & PA Semian & $\begin{array}{c}\text { Sullivan, } \\
\text { PA }\end{array}$ & sa & 58.7 & 2.80 & 0.533 & 0.027 \\
\hline ARG8 & Pocahontas & - & $1 \mathrm{vb}$ & - & 1.42 & 0.585 & 0.0203 \\
\hline DECS19 & $\begin{array}{c}\text { Pocahontas } \\
\# 3\end{array}$ & $\begin{array}{c}\text { Buchanan, } \\
\text { VA }\end{array}$ & $1 \mathrm{vb}$ & 73.3 & 1.71 & 0.654 & 0.027 \\
\hline
\end{tabular}

Table S2. Maturity and elemental analysis information for Kerogen type III Department of Energy Coal Samples (DECS), from standard coals of the Penn State Coal Bank, and Argonne Coal Bank [29-31]. 


\section{S2. Method for spectral fitting and background subtraction}

A minimum of 10 independent spots on each sample was analyzed on each sample and data were collected from 5 to 60 seconds per spot depending upon the Raman/Fluorescence intensity. The full spectral window for each acquisition is from -50 to $4000 \mathrm{~cm}^{-1}$. For the analysis, the first-order spectral window for the region relevant to carbon-based vibrations was taken from 1000 to $1800 \mathrm{~cm}^{-1}$. The background subtraction in this spectral window is performed using 2 th order polynomial functions to fit the background within the selected region $\left(1000-1800 \mathrm{~cm}^{-1}\right)$.

Peak fitting was carried out using Horiba LabSpec LabSpec 5, Horiba Scientific (http://www.horiba.com/us/en/scientific/products/ramanspectroscopy/software/functionality/). The fit is initialized with the inclusion of the D4, D5, D1, D3, G+D2 peaks (with initialization position at: 1150, 1260, 1330, 1400, 1500, 1580 and $1600 \mathrm{~cm}^{-1}$, respectively). The maximum allowed peak width is $100 \mathrm{~cm}^{-1}$. If D2 is discernible from $\mathrm{G}$, a separate peak is fit (at $\left.1600 \mathrm{~cm}^{-1}\right)$. The optimal peak fit is achieved when the standard error between the fit result and the raw data is converged to its smallest value (the converged standard error can varies depending on the level of noise in the spectra). The peaks at 1400 and 1500 may be reduced to a single peak during the fitting, if that leads to a lower standard error.

Peak fitting is carried out using PseudoVoigt profiles, a linear combination of a Gaussian and a Lorentzian [13]. The peak shape itself is parameterized between the two extremes (fully Gaussian or fully Lorentzian). Its determination through the fit allows for the identification of the nature of the statistical distribution of the vibrational frequency of a particular peak. A fully Gaussian peak will follow a normal distribution, which is expected for vibrations generated by a normal distribution of bonds with different local geometries and chemical environments. A fully Lorentzian peak fit represents a uniform individual vibration of a specific peak, with no statistical distribution around its mean. Peak intensities are averaged over multiple acquisitions for the extraction of peak intensity ratio. The reported error is the standard error of the mean.

\section{S3. Relation between $\omega_{\mathrm{G}}$ and D1/G with $\mathrm{H}: \mathrm{C}$}

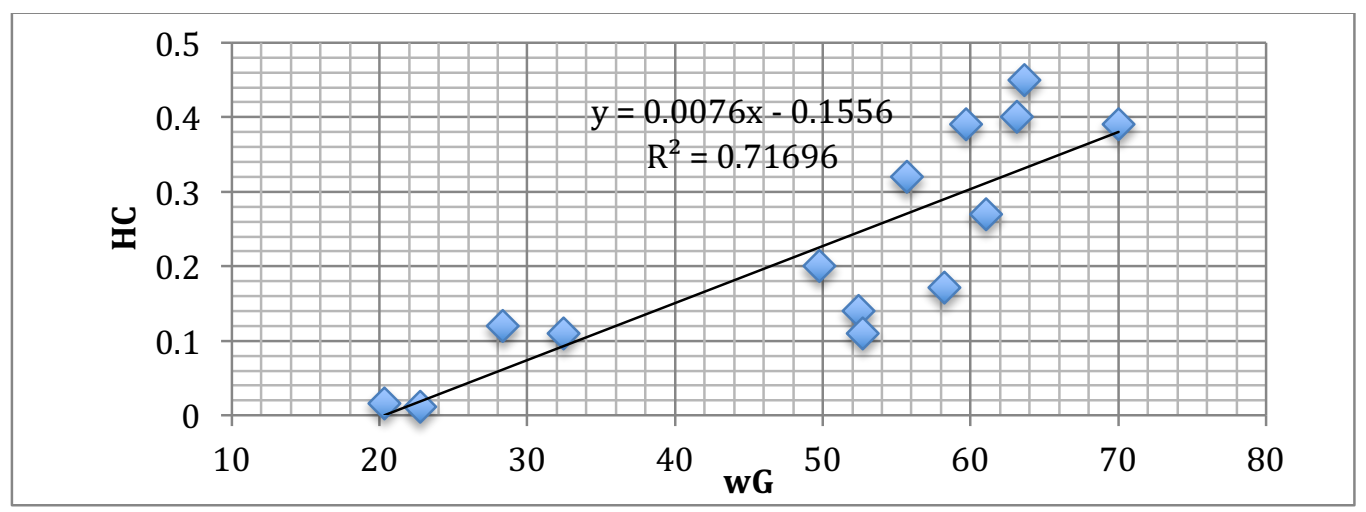

Figure S1. H:C vs $\omega_{\mathrm{G}}$ for the PPRG sample set. 
Under the assumption of pseudo-circular aromatic clusters with hydrogenated edges of the clusters, an empirical model can be constructed to evaluate the relation between the $\mathrm{H}: \mathrm{C}$ ratio and the size of aromatic clusters through a simple relation (Fig. S2): $H: C \sim 1 /$ $\omega \mathrm{G}$

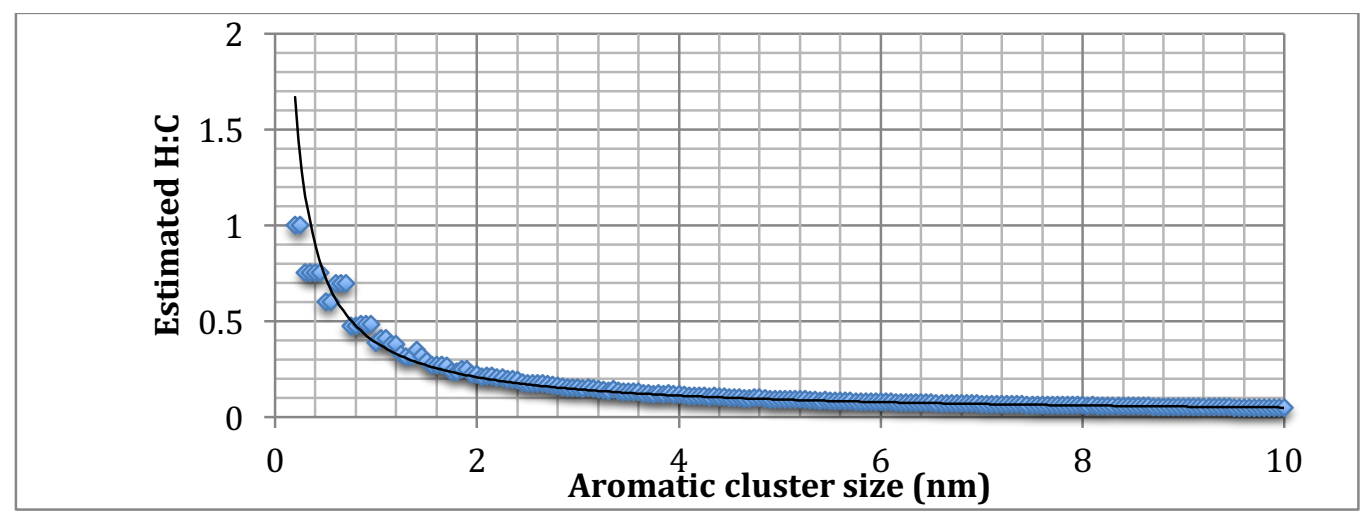

Figure S2. Relation between $\mathrm{H}: \mathrm{C}$ and the size of a round aromatic cluster

Using this relation, The D1/G peak intensity ratio can be then estimated through the Tuinstra-Koenig relation, corrected for the excitation energy [14-16]. The resulting ideal relation between D1/G and H:C is shown in Fig. S3. The complete lack of correlation as observed from the PPRG kerogen set (Fig. S4) suggests that the D1/G method to estimate $\mathrm{H}: \mathrm{C}$ is unreliable for non-metamorphic kerogen.

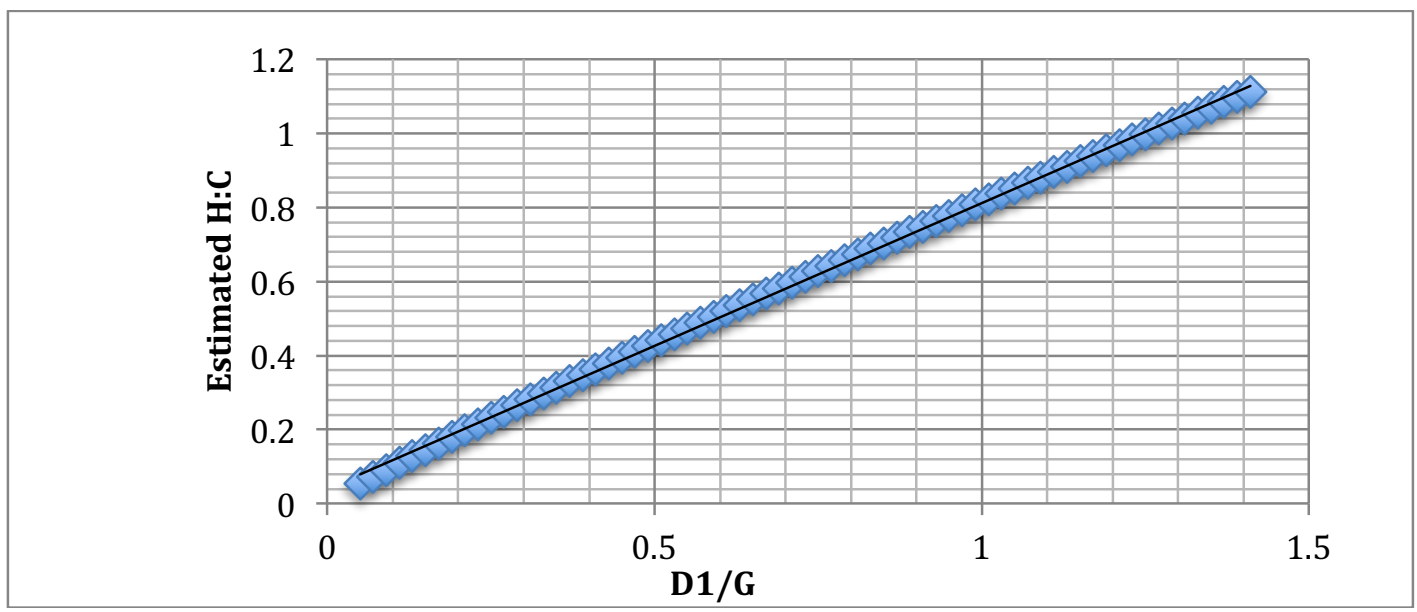

Figure S3. Ideal H:C vs D1/G for circular aromatic clusters with hydrogenated edges. 


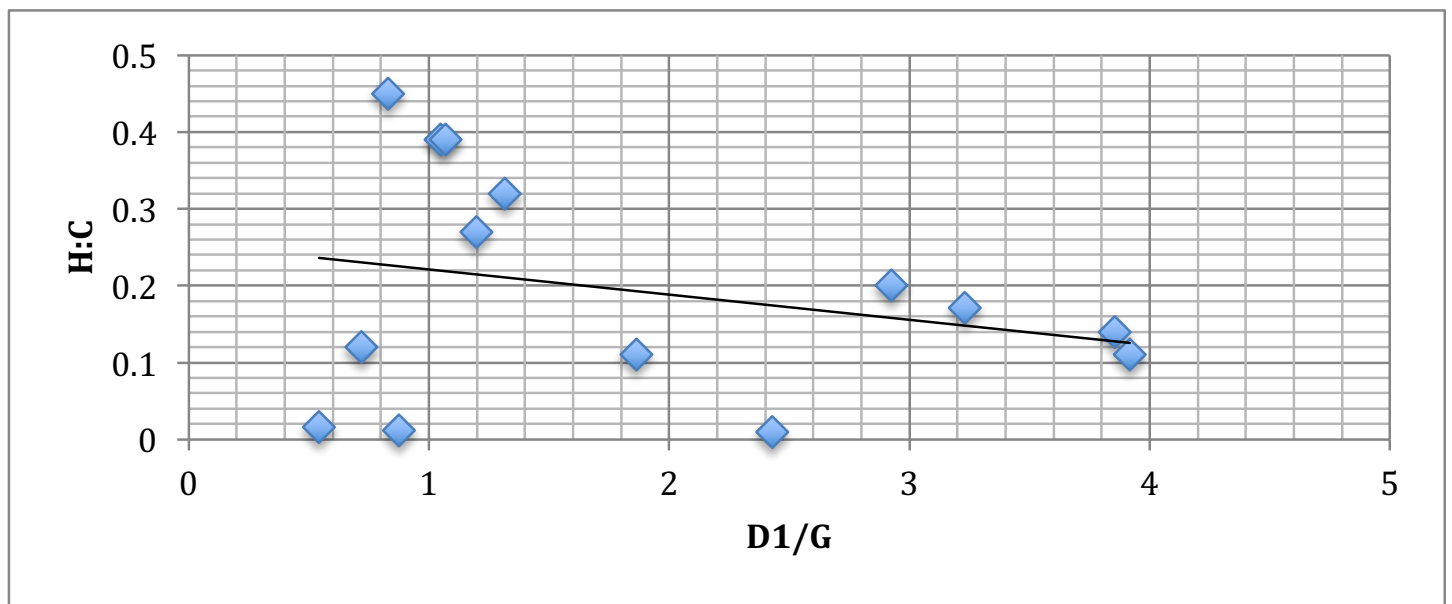

Figure S4. H:C vs D1/G for the PPRG sample set.
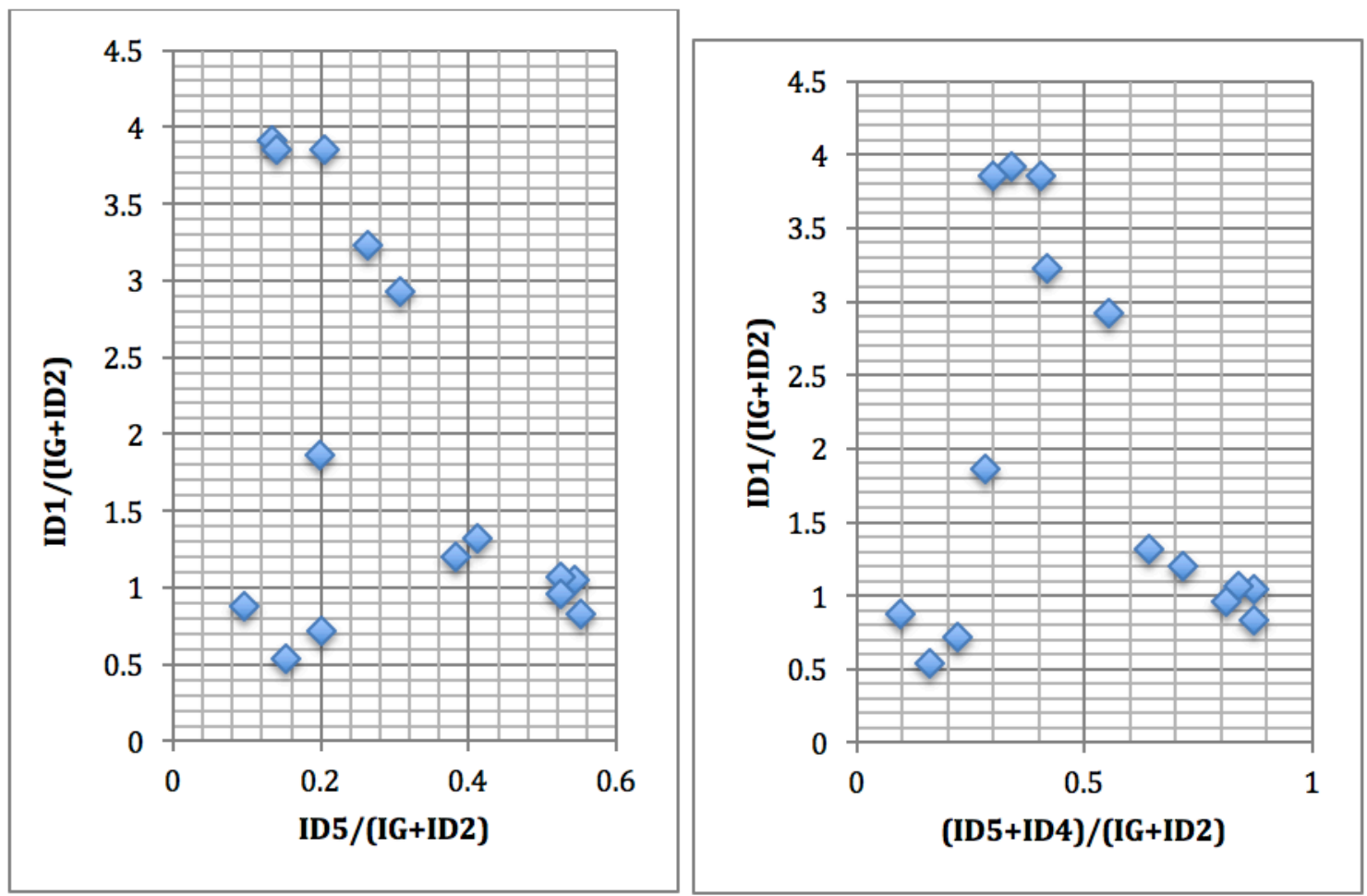

Figure S5. ID1/(IG+ID2) vs ID5/(IG+ID2) (left plot) and (ID4+ID5)/(IG+ID2) (right plot) for the PPRG sample set.

\section{S.4. Effects of heteroatoms on ID5/(IG+ID2)}




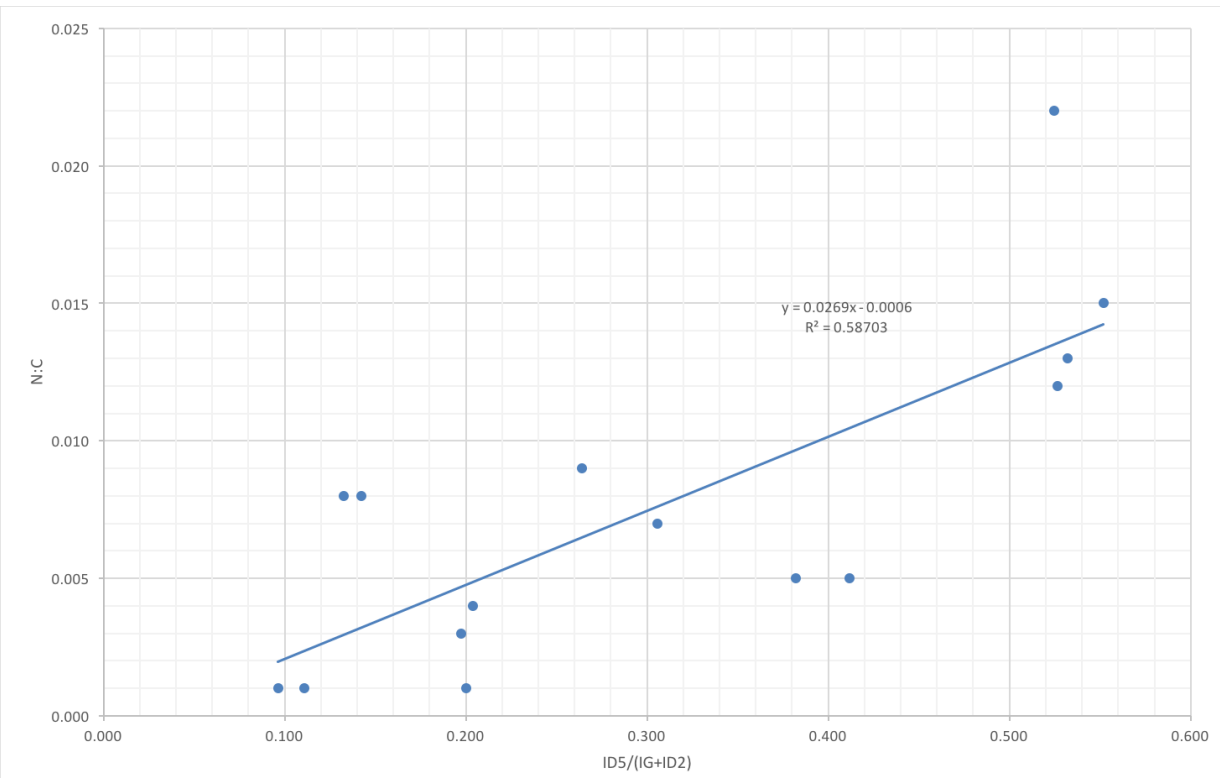

Figure S6. N:C vs ID5/(IG+ID2) for the PPRG sample set.

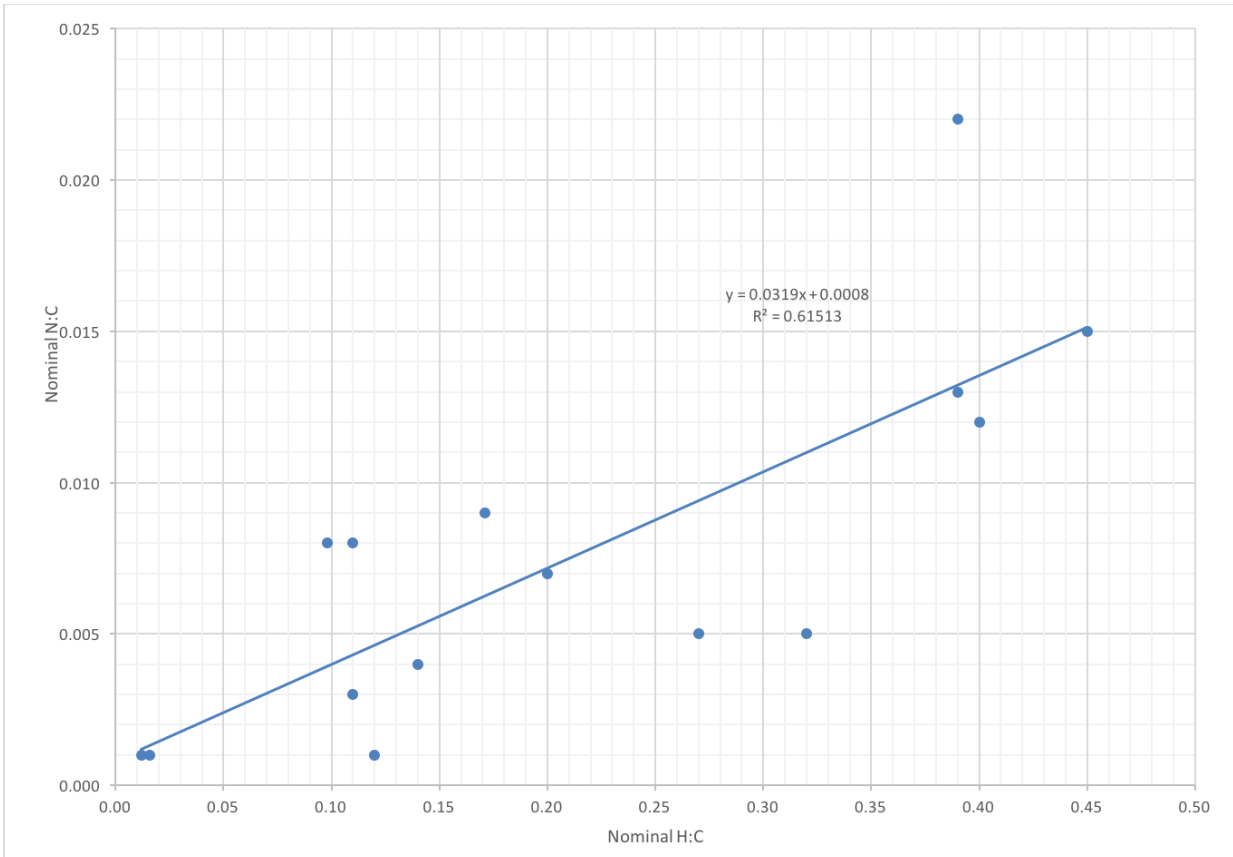

Figure S7. Nominal N:C vs Nominal H:C for the PPRG sample set. Data from Table 1.

\section{S.5. On the origin of the D4 and D5 Raman bands}

Previous attempts in assigning vibrations in the D4-D5 $\left(1100-1300 \mathrm{~cm}^{-1}\right)$ region to specific bonds or molecular compounds were limited, since they could not fully explain or cover the broad range of frequencies covered by this region. In this work, we perform the identification based on a broad range of molecular compounds of aliphatics character. A broad review literature exists regarding the identification of spectral bands in the 1200- 
$1300 \mathrm{~cm}^{-1}$ region for aliphatic compounds e.g. [17, 18]. A particularly fitting class of organic compounds, fatty acids, have been widely studied with Raman spectroscopy to evaluate their state of saturation. The Raman bands in the D4-D5 region are used as metric indicators for saturation for uses in multiple disciplines from medical diagnostics [19] to food science to characterize the type of lipids [20-23].

In this work, we used fatty acids as a proxy of molecular compounds where deformation modes of $\mathrm{CH}$ species (both $\mathrm{C}-\mathrm{H}$ and $=\mathrm{C}-\mathrm{H}$ ) typical of long saturated and unsaturated alkane chains can be found in the D4-D5 spectral region [20, 24]. Such C-H deformation modes directly relate to $\mathrm{H}: \mathrm{C}$ in aliphatics systems. However, in addition to these, several other modes exists from aliphatic compounds that directly affect $\mathrm{H}: \mathrm{C}$. Strong bands related to stretching modes $(\mathrm{v}(\mathrm{CC}))$ in alkanes appear up to $1300 \mathrm{~cm}^{-1}$, with broad variations below this frequency threshold (Chapter 2 of [18]). For example, in long chain methylene systems several twisting modes of $\mathrm{CH} 2$ modes take place in the D4-D5 region, from 1150 and $1300 \mathrm{~cm}^{-1}$ (Fig. 2.12 in [18]). The extreme diversity within different families of alkanes is consistent with the lack of a pronounced individual peak. Such variety is the result of the dependence of the coupled wagging and twisting vibrations in $\mathrm{C}-\mathrm{H}$ with the nature of the adjacent carbons, and any change in the character of such carbons will affect the twisting mode $[17,18]$. While such modes are usually very weak in IR, they are very strong for Raman. Other examples of non-aromatic compounds exist with frequencies in the D5 region: for example, allenes $\mathrm{C}=\mathrm{C}=\mathrm{C}$ stretch vibration is at $1076 \mathrm{~cm}^{-1}$ (Chapter 4 in [18]). This points to the fact that other aliphatic vibration appears to in this region. The presence of functionalities in allenes (or the use of deuterium), shows significant downwards deviations in the stretch vibration, further enriching the presence of spectral signal below 1300 [18]. Therefore, such assignment leads to a direct link between the signal strength in the D4-D5 region and $\mathrm{H}: \mathrm{C}$ uniquely from aliphatics. Since the contribution of aliphatics to the G peak is essentially absent (as $G$ is purely of aromatic character), the ratio reflects directly the amount o $\mathrm{H}: \mathrm{C}$ from aliphatics in relation to aromatics. Furthermore, any contribution from unsaturated hydrocarbons with at least one $\mathrm{C}=\mathrm{C}$ (alkenes) is not significant in the D4-D5, since most stretch vibrations appear in the region $>1650$, while out of-plane modes are in the $<990$ region, outside of the region of interest (Chapter 5 of [18]).

The question of whether $\mathrm{C}-\mathrm{H}$ in aromatics contribute directly to the D4-D5 region is addressed by noting that hydrogenated edges of aromatic clusters do not exhibit any vibration in this region (see table 5.4 in [18]). Ring stretching modes (such D1, 1330 $\mathrm{cm}^{-1}$ ) and shear modes ( $\mathrm{G}$ at $\sim 1580-1600 \mathrm{~cm}^{-1}$ ) are typical vibrations for large aromatics. The presence of atomic hydrogen on their edges does not affect the spectra. C-C stretch vibrations at aromatic edges by added methyl groups (for example in hexamethyl benzene or toluene) do not significantly affect ring stretching or shear modes [18]. It is worth nothing, however, that the actual $\mathrm{C}-\mathrm{C}$ stretch and rocking modes between the benzene ring and the methyl group in toluene occurs in the D4-D5 region 1040 and 1155, 1200 [25]. In this case, as for aliphatics, the additional methyl group on the benzene ring is accounted in the D4-D5 in the total H:C. 
In essence, the observed correlation between (D4+D5)/G or D5/G and $\mathrm{H}: \mathrm{C}$ is a direct representation of the concentration of $\mathrm{CH}$ species (and therefore also methyl groups) in aliphatics or aliphatic chains attached to aromatic clusters. If the material would have no aliphatic moieties (i.e. purely aromatics), H:C would be determined uniquely by the hydrogen termination at edges around small aromatic clusters (as discussed in the elswhere), which for extended aromatic systems, it is very low. If the same clusters would include aliphatic chains (or alicyclics) the significant increase in D4-D5 as a result from a diverse set of vibrations associated with these molecules, leads to the increase in $\mathrm{H}: \mathrm{C}$ that is indeed observed. This is consistent with the observation of strong vibrations in the lattice of fatty acids, and in general to aliphatic systems, in the region of relevance.

\section{S.6. Decoupling aromatic ordering and nanostructure from $\mathrm{H}$ :C through the Raman spectra}

The striking difference in the Raman spectra of two different samples whose OM carries the same $\mathrm{H}: \mathrm{C}$ ratio is shown through two examples, within the PPRG sample set (Fig. S6) and the DECS coal sample set (Fig. S7). We highlight the spectral fits for PPRG-048 (Fig. S7) and PPRG-266 (Fig. S8) as well as DECS-21 (Fig. S10) and DECS-1515 (Fig. $\mathrm{S} 11)$. The extracted value of $\mathrm{H}: \mathrm{C}$ from $\mathrm{ID} 5 /(\mathrm{IG}+\mathrm{iD} 2)$ is very similar for the two PPRG and DECS samples and nearly identical to their nominal value $(0.11$ and 0.533 for the PPRG and DECS samples, respectively), despite the significant spectral differences.

Further insight on the nanostructure can be gained by analyzing the shape of the fitting profile of each single peak. By purposefully avoiding constraining the shape of the peak to either a Lorentzian or a Gaussian through the use of a Pseudo-Voigt profile, we find that D1 is usually a perfect Gaussian regardless of the type of organic matter or its maturity. This is consistent with the defect-induced activation of the peak, as it originates from a stochastic distribution of electronic and vibrational states around defects. The $G$ peak however shows a higher degree of variability. For highly graphitic organic matter (PPRG-266, Fig. S6) the shape of G is purely Lorentzian: this is consistent with the peak arising from a single shear vibration within the aromatic plane. For slightly less ordered organic matter (PPRG-048, Fig. S6), there is a 10\% Gaussian component in the G peak that can be associated with a small distribution of vibrational frequencies around for the $\mathrm{G}$ peak in perfect graphite, possibly induced by deformations, strain or defects. This is consistent with a system where we can no longer associate aromatic clusters with extended graphene sheets, but with aromatic clusters with different size and shape; therefore no single vibration is effectively responsible for the $G$ peak and its increased width. 


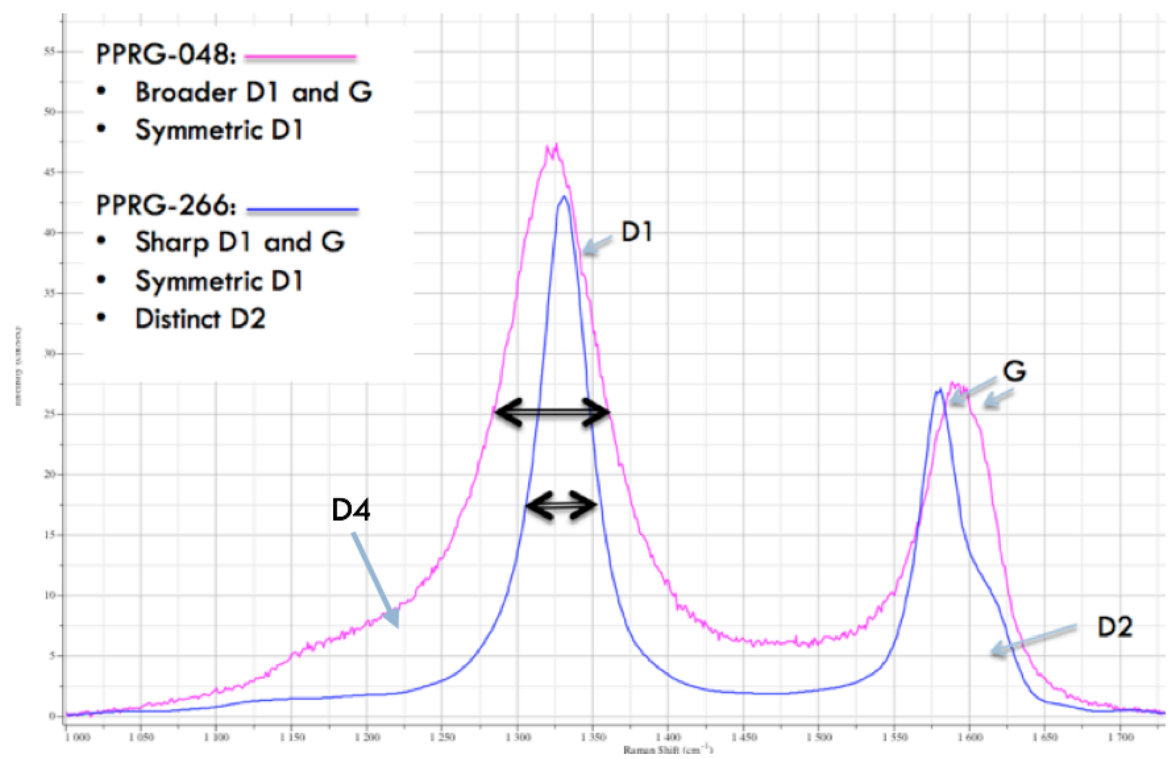

Figure S8. Comparison between the Raman spectra of two different OM from the PPRG set, with the same $\mathrm{H}: \mathrm{C}(0.11)$.

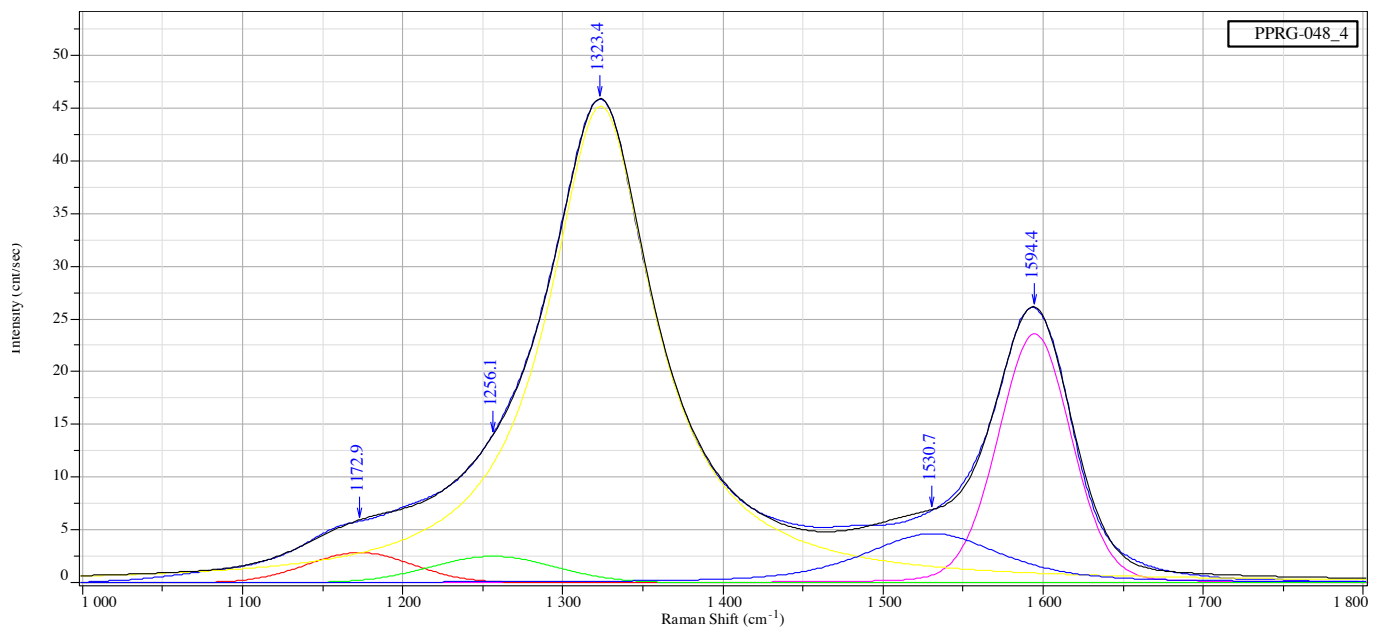

Figure S9. Spectral peak fitting for a typical spectra of PPRG-048. The H:C $=0.102$ is determined through ID5/(IG+ID2) $=0.174$ (nominal value $=0.11)$. When $(\mathrm{ID} 4+\mathrm{ID} 5) /(\mathrm{IG}+\mathrm{ID} 2)=0.33$ is used, the estimated $\mathrm{H}: \mathrm{C}=0.124$. 


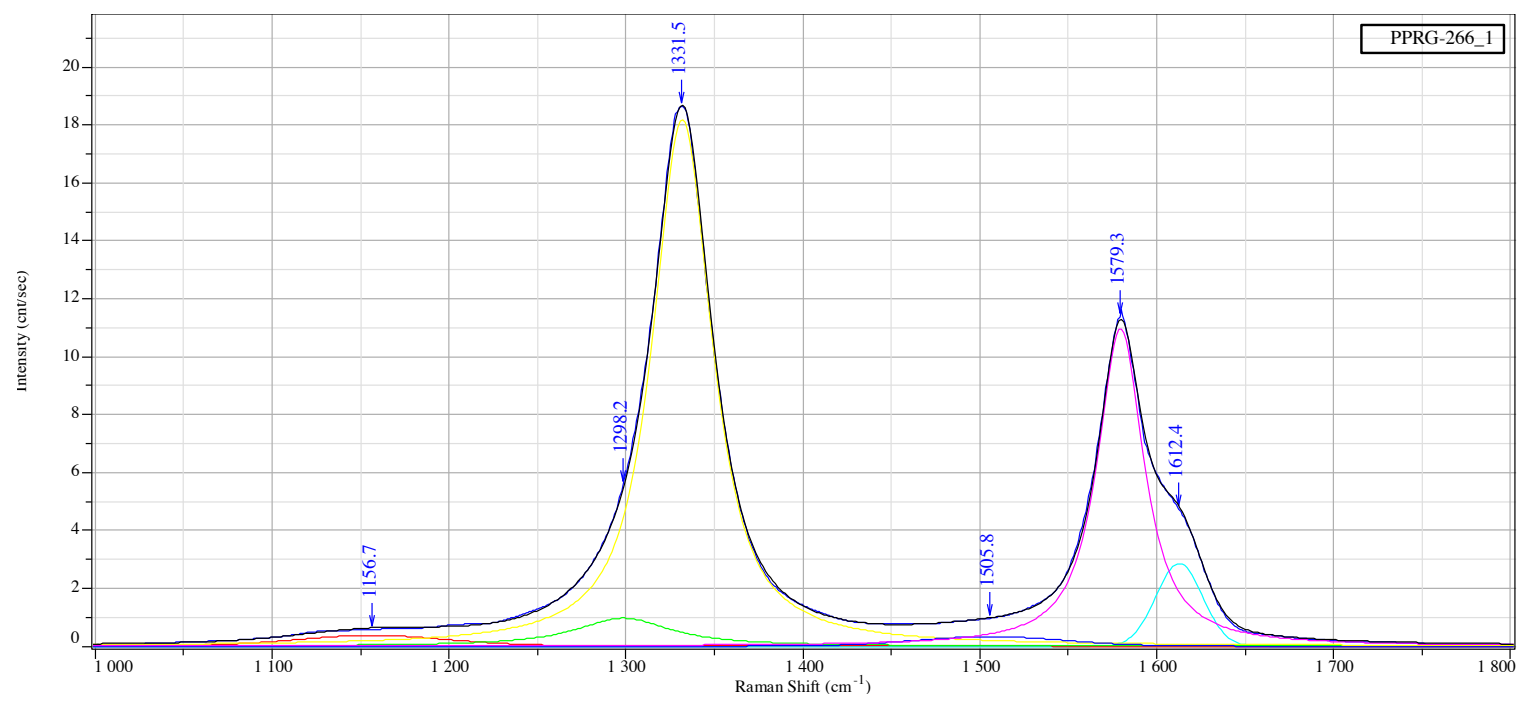

Figure S10. Spectral peak fitting for a typical spectra of PPRG-266. The $\mathrm{H}: \mathrm{C}=0.101$ is determined through ID5/(IG+ID2) $=0.173($ nominal value $=0.11)$. When $(\mathrm{ID} 4+\mathrm{ID} 5) /(\mathrm{IG}+\mathrm{ID} 2)=0.284$ is used, the estimated $\mathrm{H}: \mathrm{C}=0.097$.

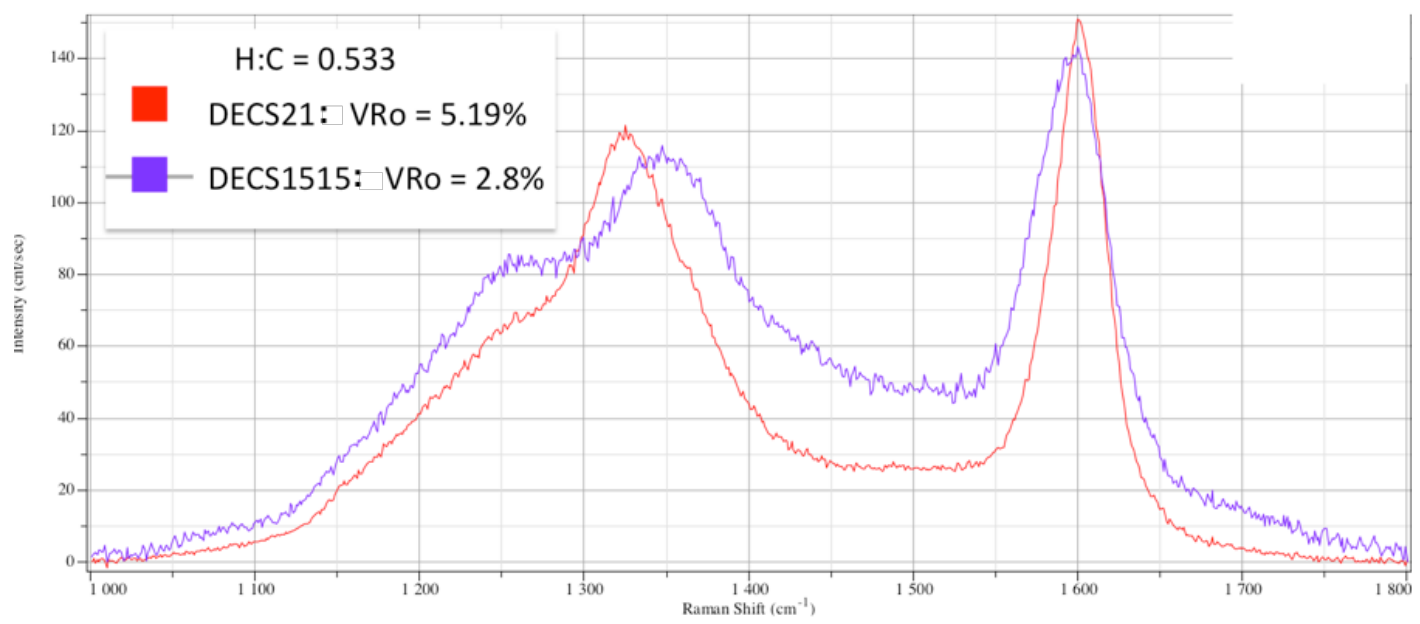

Figure S11. Comparison between the Raman spectra of OM in two different samples from the DECS coal collection (details in S.5) with the same H:C (0.533). 


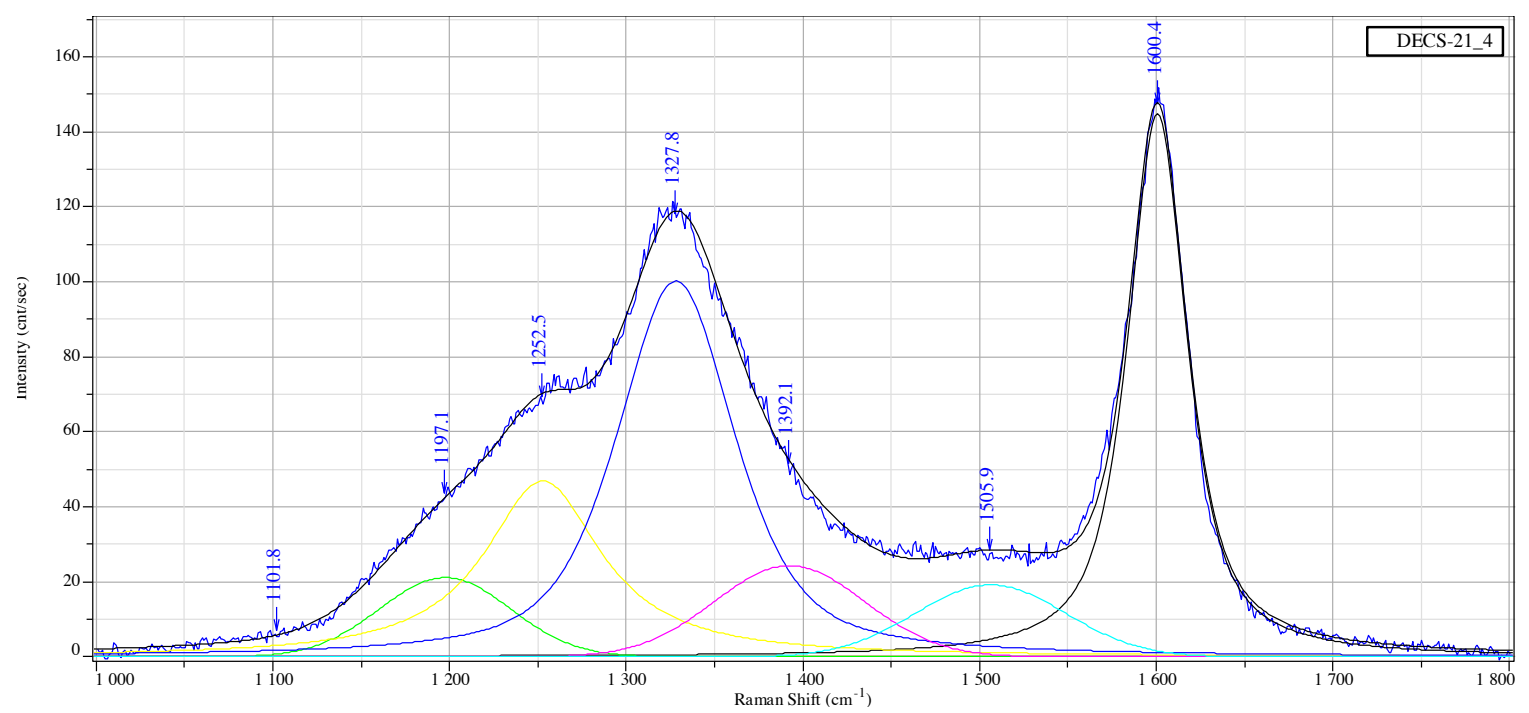

Figure S12. Spectral peak fitting for a typical spectra of DECS-21. The H:C $=0.539$ is determined through ID5/(IG+ID2) $=0.677($ nominal value $=0.533)$.

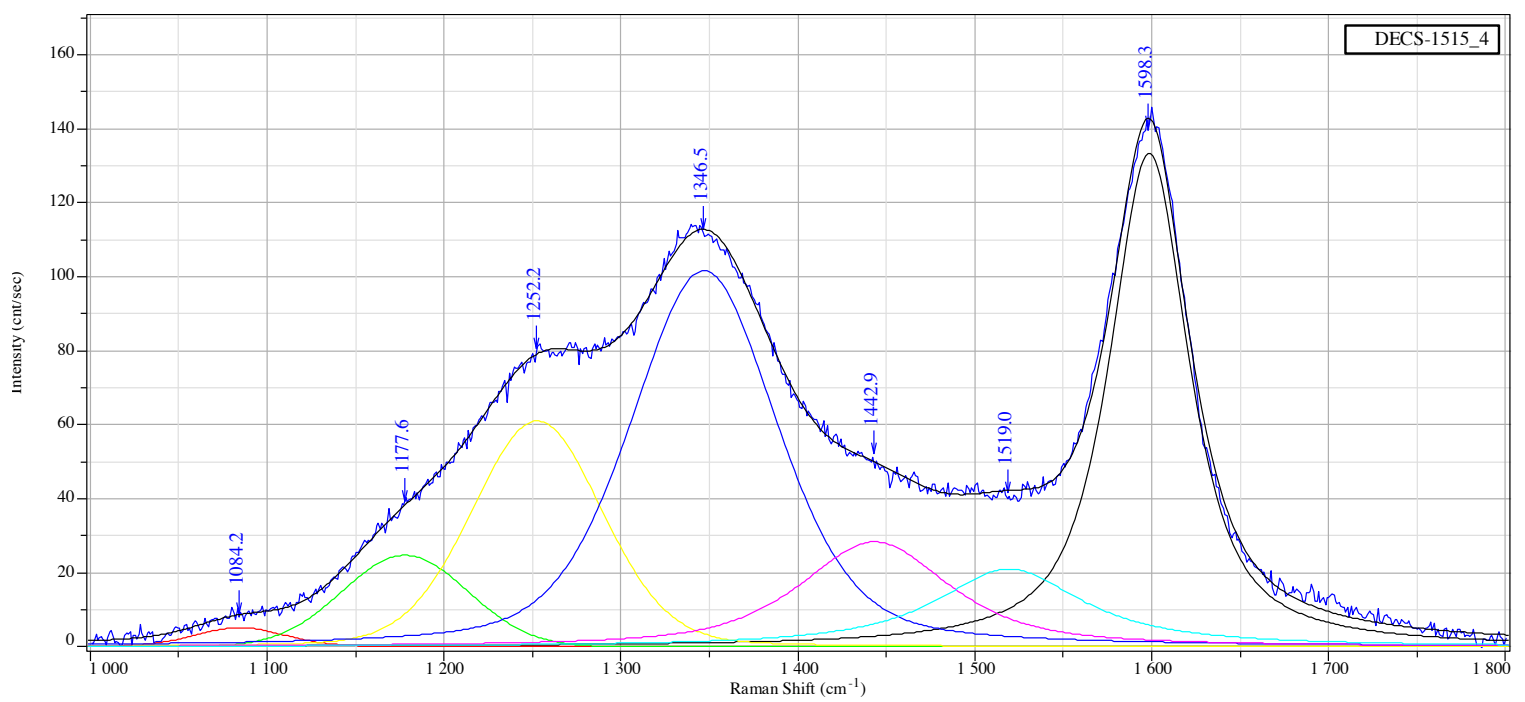

Figure S13. Spectral peak fitting for a typical spectra of DECS-1515. The H:C $=0.522$ is determined from ID5/(IG+ID2) $=0.658$ (nominal value $=0.533)$.

\section{S.7 Direct probing of OM H:C in the presence of mineral contamination}

Conventionally, OM extracted from source rocks through acid attacks may leave inorganic or aqueous residues. The hydrogen content in the residue (not related to OM) or additional carbon residue (from incomplete demineralization of carbonates) may lead to under/overestimation of $\mathrm{H}: \mathrm{C}$ from $\mathrm{OM}$. The $\mathrm{D} 5 / \mathrm{G}$ vs $\mathrm{H}: \mathrm{C}$ relationship is based strictly on $\mathrm{H}$ and $\mathrm{C}$ in the $\mathrm{OM}$ regardless of the presence of inorganic or aqueous residue. To show the extent of such discrepancy, the $\mathrm{D} 5 / \mathrm{G}$ ratio measured from the AIDP kerogen sample 
set is plotted against their nominal H:C from elemental analysis (Fig. S.12). AIDP kerogen was isolated from the carbonate matrix through hydrochloric and hydrofluoric acid, leaving a strong $\mathrm{CaF}_{2}$ presence along with water. This is likely due to incomplete removal of carbonates or insufficient washing of some samples prior to treatment with HF. The discrepancy in the measured $\mathrm{H}: \mathrm{C}$ compared to the projected $\mathrm{H}: \mathrm{C}$ in the actual $\mathrm{OM}$ points to resilience and insensitivity of this method towards contamination.

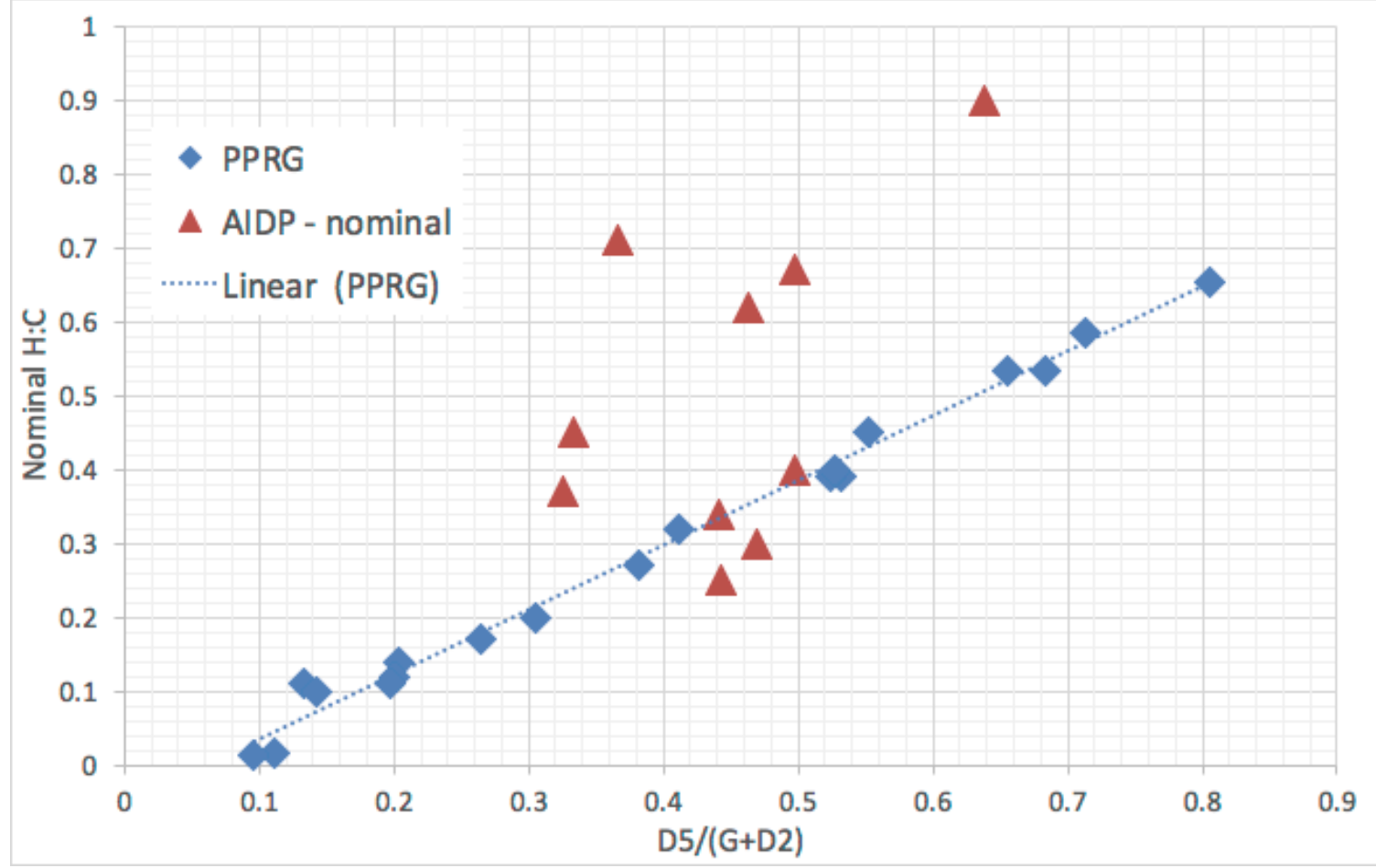

Figure S14. H:C vs D5/(G+D2) for the PPRG and AIDP sample sets. H:C for the AIDP obtained through elemental analysis shows a large discrepancy compared to the PPRG set. The AIDP samples with high $\mathrm{H}: \mathrm{C}$ also have a strong $\mathrm{CaF}_{2}$ signal response.

\section{S.8 Cluster analysis}

Phase-based correlations among several Raman spectral features are statistically analyzed using cluster analysis [26-28]. In cluster analysis, the number of clusters or phases in a dataset can be identified along with the uncertainty of observations belonging to a cluster based on statistical criteria. The approach followed in this study is based on mixture modeling and implements maximum likelihood estimation and Bayesian Information Criteria (BIC) to identify the most likely model and the number of clusters.

In this method, each event $x_{i}$ is comprised of Raman spectral features such as peak ratios (D1/G, D5/G, D TOT $/ \mathrm{G},(\mathrm{D} 4+\mathrm{D} 5) / \mathrm{G})$, peak width (FWHM G peak, $\omega_{\mathrm{G}}$ ), peak intensities $(\mathrm{D} 1, \mathrm{D} 4, \mathrm{D} 5, \mathrm{G})$ and $\mathrm{H}: \mathrm{C}$ ratios. Each event $x_{i}$ is considered to be a realization of the random multi-dimensional vector $X=\left(X_{1}^{T}, \ldots, X_{n}^{T}\right)$, where $\mathrm{n}$ is the total number of events 
(i.e. total number of points in a Raman map). The probability density function $f\left(x_{i}\right)$ of the observed data $x_{i}$ in $X_{i}$ in a G-component mixture is

$$
f\left(x_{i}, \Psi\right)=\sum_{k=1}^{g} \tau_{k} \phi\left(x_{i} ; \mu_{k}, \Sigma_{k}\right)
$$

where $\tau_{k}$ is the probability that an observation belongs to the $k$-th component $\left(\sum_{k=1}^{G} \tau_{k}=\right.$ 1 ), $\Psi=\left(\tau_{1}, \ldots, \tau_{k}, \xi^{T}\right)^{T}$ with $\xi$ containing the (unknown) group mean $\mu_{k}$ and the covariance matrix $\boldsymbol{\Sigma}_{k}$ and $\phi\left(x_{i} ; \mu_{k}, \Sigma_{k}\right)$ corresponding to the multi-variate normal density

$$
\phi\left(x_{i}, \mu_{k}, \Sigma_{k}\right)=\frac{\exp \left(-\frac{1}{2}\left(x_{i}-\mu_{k}\right)^{T}\left(\Sigma_{k}\right)^{-1}\left(x_{i}-\mu_{k}\right)\right)}{\sqrt{\operatorname{det}\left(2 \pi \boldsymbol{\Sigma}_{k}\right)}}
$$

The likelihood for data consisting of $n$ independent observations assuming normal mixture model with $G$ components is given by:

$\prod_{i=1}^{n} \sum_{k=1}^{G} \tau_{k} \phi\left(x_{i}, \mu_{k}, \mathbf{\Sigma}_{k}\right)$

The best model is identified by fitting models with differing parameterization and/or number of components to the data by maximum likelihood, and then by implementing a statistical criterion for model selection, (here Bayesian Information Criteria (BIC)).

\section{References}

[1] Des Marais DJ. Isotopic Evolution of the Biogeochemical Carbon Cycle During the Precambrian. Reviews in Mineralogy and Geochemistry. 2001;43(1):555-78.

[2] Walter MR, Hofmann HJ, Schopf JW. Apendix 1; Geographic and geologic data for processed samples. In: Schopf JW, ed. Earth's earliest biosphere. Princeton, N.J.: Princeton University Pres 1983, p. 385-414.

[3] Wedeking KW, Hayes JM, Matzigkeit U. Procedures of Organic Geochemical Analysis. In: Schopf JW, ed. Earth 's Earliest Biosphere: Its Origin and Evolution. Princeton: Princeton Univ. Press 1983, p. 428-41.

[4] Hayes JM, Kaplan IR, Wedeking KW. Precambrian organic geochemistry: Preservation of the record. In: Schopf JW, ed. Earth 's Earliest Biosphere: Its Origin and Evolution. Princeton: Princeton Univ. Press 1983, p. 93-135.

[5] Anbar AD, Duan Y, Lyons TW, Arnold GL, Kendall B, Creaser RA, et al. A Whiff of Oxygen Before the Great Oxidation Event? Science. 2007;317(5846):1903-6.

[6] Buick R, Anbar AD, Mojzsis SJ, Kaufman AJ, Kieft TL, Lyons TW, et al. The case for scientific drilling of Precambrian sedimentary sequences: A mission to early Earth. American Geophysical Union, Fall Meeting 2001, abstract \#P22B-0544. 2004. [7] Beukes NJ, Evans DAD, Grotzinger JP, Kirschvink JL, Knoll AH, Sumner DY. Multidisciplinary Study Of The Precambrian Biosphere And Surficial Oxygenation, 
Kaapvaal Craton, South Africa: The Agouron Cores. International Journal of Astrobiology, Supplement. 2004;15.

[8] Fischer WW, Schroeder S, Lacassie JP, Beukes NJ, Goldberg T, Strauss H, et al. Isotopic constraints on the Late Archean carbon cycle from the Transvaal Supergroup along the western margin of the Kaapvaal Craton, South Africa. Precambrian Research. 2009;169(1-4):15-27.

[9] Waldbauer JR, Sherman LS, Sumner DY, Summons RE. Late Archean molecular fossils from the Transvaal Supergroup record the antiquity of microbial diversity and aerobiosis. Precambrian Research. 2009;169:28-47. [10] Simonson BM, Sumner DY, Beukes NJ, Johnson S, Gutzmer J. Correlating multiple Neoarchean-Paleoproterozoic impact spherule layers between South Africa and Western Australia. Precambrian Research. 2009;169(1-4):100-11.

[11] Knoll AH, Beukes NJ. Introduction: Initial investigations of a Neoarchean shelf margin-basin transition (Transvaal Supergroup, South Africa). Precambrian Research. 2009;169(1-4):1-14.

[12] French KL, Hallmann C, Hope JM, Schoon PL, Zumberge JA, Hoshino Y, et al. Reappraisal of hydrocarbon biomarkers in Archean rocks. Proceedings of the National Academy of Sciences. 2015;112(19):5915-20.

[13] Ida T, Ando M, Toraya H. Extended pseudo-Voigt function for approximating the Voigt profile. Journal of Applied Crystallography. 2000;33(6):1311-6.

[14] Tuinstra F, Koenig JL. Raman Spectrum of Graphite. The Journal of Chemical Physics. 1970;53:1126-30.

[15] Pimenta MA, Dresselhaus G, Dresselhaus MS, Cancado LG, Jorio A, Saito R. Studying disorder in graphite-based systems by Raman spectroscopy. Physical Chemistry Chemical Physics. 2007;9(11):1276-90.

[16] Martins Ferreira EH, Moutinho MVO, Stavale F, Lucchese MM, Capaz RB, Achete CA, et al. Evolution of the Raman spectra from single-, few-, and many-layer graphene with increasing disorder. Physical Review B. 2010;82(12):125429.

[17] Long DA. Raman spectroscopy: McGraw-Hill; 1977.

[18] Mayo DW, Miller FA, Hannah RW. Course Notes on the Interpretation of Infrared and Raman Spectra: John Wiley \& Sons, Inc.; 2003.

[19] Frank CJ, McCreery RL, Redd DCB. Raman Spectroscopy of Normal and Diseased Human Breast Tissues. Analytical Chemistry. 1995;67(5):777-83.

[20] Baeten V, Hourant P, Morales MT, Aparicio R. Oil and Fat Classification by FTRaman Spectroscopy. Journal of Agricultural and Food Chemistry. 1998;46(7):263846.

[21] Afseth NK, Wold JP, Segtnan VH. The potential of Raman spectroscopy for characterisation of the fatty acid unsaturation of salmon. Analytica Chimica Acta. 2006;572(1):85-92.

[22] Dong W, Zhang Y, Zhang B, Wang X. Rapid prediction of fatty acid composition of vegetable oil by Raman spectroscopy coupled with least squares support vector machines. Journal of Raman Spectroscopy. 2013;44(12):1739-45. [23] Olsen EF, Rukke E-0, Flåtten A, Isaksson T. Quantitative determination of saturated-, monounsaturated- and polyunsaturated fatty acids in pork adipose tissue with non-destructive Raman spectroscopy. Meat Science. 2007;76(4):628-34. 
[24] Koyama Y, Ikeda K-i. Raman spectra and conformations of the cisunsaturated fatty-acid chains. Chemistry and Physics of Lipids. 1980;26(2):149-72. [25] Wilmshurst JK, Bernstein HJ. The infrared and Raman spectra of toluene, toluene $\alpha$-d3, m-xylene and m-xylene- $\alpha \alpha^{\prime}$-d6. Canadian Journal of Chemistry. 1957;35(8):911-25.

[26] Fraley C, Raftery AE. MCLUST: Software for Model-Based Cluster Analysis. J of Classification. 1999;16(2):297-306.

[27] Fraley C, Raftery AE. Model-Based Clustering, Discriminant Analysis, and Density Estimation. Journal of the American Statistical Association. 2002;97(458):611-31.

[28] Fraley C, Raftery AE. Model-based methods of classification: using the mclust software in chemometrics. Journal of Statistical Software. 2007;18: 1-13.

[29]. Argonne Premium Coal Bank (2012), now handled by the PSU Coal Bank. Analytical data: http://web.anl.gov/PCS/report/part2.html

[30]. Herrin, J.M., Deming D., Thermal Conductivity of U.S. Coals, 1996, Journal of Geophysical Research v. 101, No B11 pp. 25381-25386

[31]. Penn State Coal Bank (2012), Energy Institute, Penn State University. Analytical data: http://www.energy.psu.edu/sites/default/files/files/CSB_Fact\%20Sheet.pdf 